\title{
Recent Progress in the Development of Advanced Functionalized Electrodes for Oxygen Evolution Reaction: An Overview
}

\author{
Tse-Wei Chen ${ }^{1}$, Palraj Kalimuthu ${ }^{2}\left(\mathbb{D}\right.$, Ganesan Anushya ${ }^{3}$, Shen-Ming Chen ${ }^{4, *(D)}$, Vinitha Mariyappan ${ }^{4}(\mathbb{D})$ and \\ Rasu Ramachandran ${ }^{5, *}$
}

check for updates

Citation: Chen, T.-W.; Kalimuthu, P.; Anushya, G.; Chen, S.-M.;

Mariyappan, V.; Ramachandran, R. Recent Progress in the Development of Advanced Functionalized Electrodes for Oxygen Evolution Reaction: An Overview. Materials 2021, 14, 4420. https://doi.org/ $10.3390 /$ ma14164420

Academic Editors: Vincenzo Baglio and Carmelo Lo Vecchio

Received: 30 June 2021

Accepted: 3 August 2021

Published: 6 August 2021

Publisher's Note: MDPI stays neutral with regard to jurisdictional claims in published maps and institutional affiliations.

Copyright: (c) 2021 by the authors. Licensee MDPI, Basel, Switzerland. This article is an open access article distributed under the terms and conditions of the Creative Commons Attribution (CC BY) license (https:// creativecommons.org/licenses/by/ $4.0 /)$.
1 Department of Materials, Imperial College London, London SW7 2AZ, UK; t.chen19@imperial.ac.uk

2 School of Chemistry and Molecular Biosciences, University of Queensland, Brisbane 4072, Australia; p.kalimuthu@uq.edu.au

3 Department of Physics, S.A.V. Sahaya Thai Arts and Science (Women) College, Sahayam Nagar, Kumarapuram Road, Vadakkankulam, Tirunelveli 627116, India; anushya@savsahayathaicollege.com

4 Electroanalysis and Bioelectrochemistry Lab, Department of Chemical Engineering and Biotechnology, National Taipei University of Technology, No.1, Section 3, Chung-Hsiao East Road, Taipei 106, Taiwan; vinithavicky80@gmail.com

5 Department of Chemistry, The Madura College, Vidya Nagar, Madurai 625011, India

* Correspondence: smchen@ntut.edu.tw (S.-M.C.); ramachandran@maduracollege.edu.in (R.R.)

\begin{abstract}
Presently, the global energy demand for increasing clean and green energy consumption lies in the development of low-cost, sustainable, economically viable and eco-friendly natured electrochemical conversion process, which is a significant advancement in different morphological types of advanced electrocatalysts to promote their electrocatalytic properties. Herein, we overviewed the recent advancements in oxygen evolution reactions (OERs), including easy electrode fabrication and significant action in water-splitting devices. To date, various synthetic approaches and modern characterization techniques have effectively been anticipated for upgraded OER activity. Moreover, the discussed electrode catalysts have emerged as the most hopeful constituents and received massive appreciation in OER with low overpotential and long-term cyclic stability. This review article broadly confers the recent progress research in OER, the general mechanistic approaches, challenges to enhance the catalytic performances and future directions for the scientific community.
\end{abstract}

Keywords: advanced electrocatalysts; fabrication technique; nanocomposite; oxygen evolution reaction; cyclic stability

\section{Introduction}

There have been significant developments of clean and green energy and more efficient renewable sources, which include electrochemical conversions and storage methods in the fields of solar cells [1], fuel cells [2] and batteries [3], etc. To reach the next level energy conversion process, there needs to be a cost-effective manner for sustainable energy, which can fulfil the global energy demands [4]. High performance-based novel types of electrode catalysts have been developed for oxygen evolution reactions (OERs), specifically in oxides [5], hydroxides [6], sulfides [7] and phosphides [8]. These types of electrode catalysts have been specifically designed to achieve more active electrode surfaces to boost their electrocatalytic activities during the electrochemical process. The general mechanism of major important electrochemical energy devices for the hydrogen and oxygen evolution reactions are the key parameters that occur at both the anode and cathode electrode materials for hydrogen production through the water-splitting process, which is discussed in more detail in Section 5 [9].

Yuan Li and co-workers [10] electrochemically fabricated the microporous bi-continuous structure of phosphorous-doped $\left(\mathrm{P}-\left(\mathrm{PbO}_{2}-\mathrm{MnO}_{2}\right)\right)$ composite electrodes for the study of 
OER activities, and the possible oxygen evolution mechanism was also highlighted. Ahigh surfacearea-based iridium (Ir) scaffold with activated carbon composite electrocatalysts was prepared by pyrolysis method, with the synergetic effect of this composite as the electrode for oxygen reduction reaction (ORR) in seawater electrolysis [11]. At present, novel 2D-structured $\mathrm{NiO} / \mathrm{CeO}_{2}$ bi-functional electrocatalysts have been studied in OER activities, because of the large contact area they provide, thereby improving the adsorption and splitting of water molecules [12]. Yang and co-workers demonstrated that novel and highly stable tri-metallic $\mathrm{NiFeCr}$ electrocatalysts enhance the intrinsic OER catalytic activity and long-term cyclic durability during OER studies [13]. The bi-functional natures of hollow structured $\mathrm{Ni} @ \mathrm{NiCo}_{2} \mathrm{O}_{4}$ electrocatalysts have received considerable attention for OER studies. However, the constructed novel electrocatalyst can exhibit a high surface area, faster electron transport and anachieved current density value of $10 \mathrm{~mA} \mathrm{~cm}{ }^{-2}$ [14].

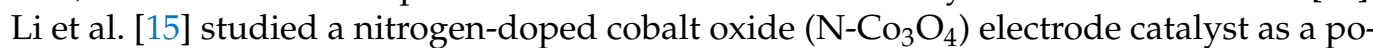
tential candidate for OER. Here, the doping mechanism of nitrogen with metal oxides can significantly improve the $\mathrm{OH}^{-}$adsorption capability, increasing electronic conductivity and excellent OER performances with good cyclic stability. Broicher et al. [16] showed an

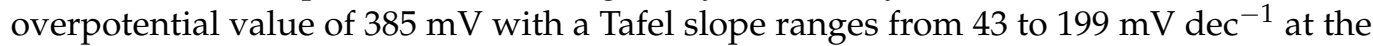
recorded current density value of $10 \mathrm{~mA} \mathrm{~cm}^{-2}$ for a spinel structure of a mesoporous nickel cobalt oxide $\left(\mathrm{NiCO}_{2} \mathrm{O}_{4}\right)$ catalyst. The highly desirable, active and robust vertically aligned cobalt-molybdenum-supported gold ( $\mathrm{AuNPs} / \mathrm{CoMoN}_{x}$ ) nanocomposite was explored with a large accessible surface area and high intrinsic activity. The synthesized nanocomposite facilitates fast electron transfer process with remarkable OER catalytic activity under alkaline conditions [17]. A fast and facile heterogeneous-based tannin-NiFe(TANF) complex film was fabricated, which can be modified with carbon paper (CP). After the fabrication process, TA-metal complex film composites were considered as the new-type OER active electrocatalysts [18]. Interestingly, a nitrogen-enriched graphene quantum dots (C-GQDs) catalyst was developed with an efficient electrocatalytic activity, and the charge distribution of pyridine and pyridine $\mathrm{N}$-oxide is induced through the $\pi-\pi$ delocalization process, which could encourage their OER activity [19]. Surendran et al. [20] hydrothermally synthesized the spherically nanostructured carbon-enriched cobalt phosphide multi-functional electrode for water electrolyzer studies, and reported the current density of $10 \mathrm{~mA} \mathrm{~cm}{ }^{-2} @ 1.63$ V. Qian et al. [21] prepared a cost-effective, larger specific surface area with high electrically conductive natured MWCNTs for the making of a thermo-electrochemical (TEC) catalyst by the electrochemical deposition (EPD) method. The prepared MWCNT TEC catalyst could display a high power density $\left(45.2 \mathrm{~A} \mathrm{~cm}^{-2}\right)$ with long-term cyclic stability. The high synergetic-based MWCNT bucky paper and MWCNT forest electrode materials were used for the harvesting of high thermo-electrochemical cells from waste thermal energy resources. Moreover, the MWCNT forest temperament electrode significantly enhanced the thermo cell efficiency by $30 \%$ which is more than that of the MWCNT bucky paper electrode [22]. The OER is a promising energy storage device and for the production of fuel $\mathrm{H}_{2}$ based on the water splitting process (Scheme 1) [9]. Table S1 presents synthesis routes, electrolytes and some of the important electrochemical parameters related to the advanced electrocatalysts for OER.

In this regard, the current advancement research in OER studies, using functionalized, highly electroactive catalysts, are summarized, which include the design, detailed mechanism, characterization, evaluation and various techniques used for assembling advanced electrocatalysts and also sensibly increasing their electrocatalytic properties, whichwill help the scientific community. Based on this fruitful discussion, we briefly present the current challenges and the significant achievements in the OER catalyst. The futuristic scopes of research strategies for determining electrocatalytic activity with the stability of advanced catalysts are highlighted. 


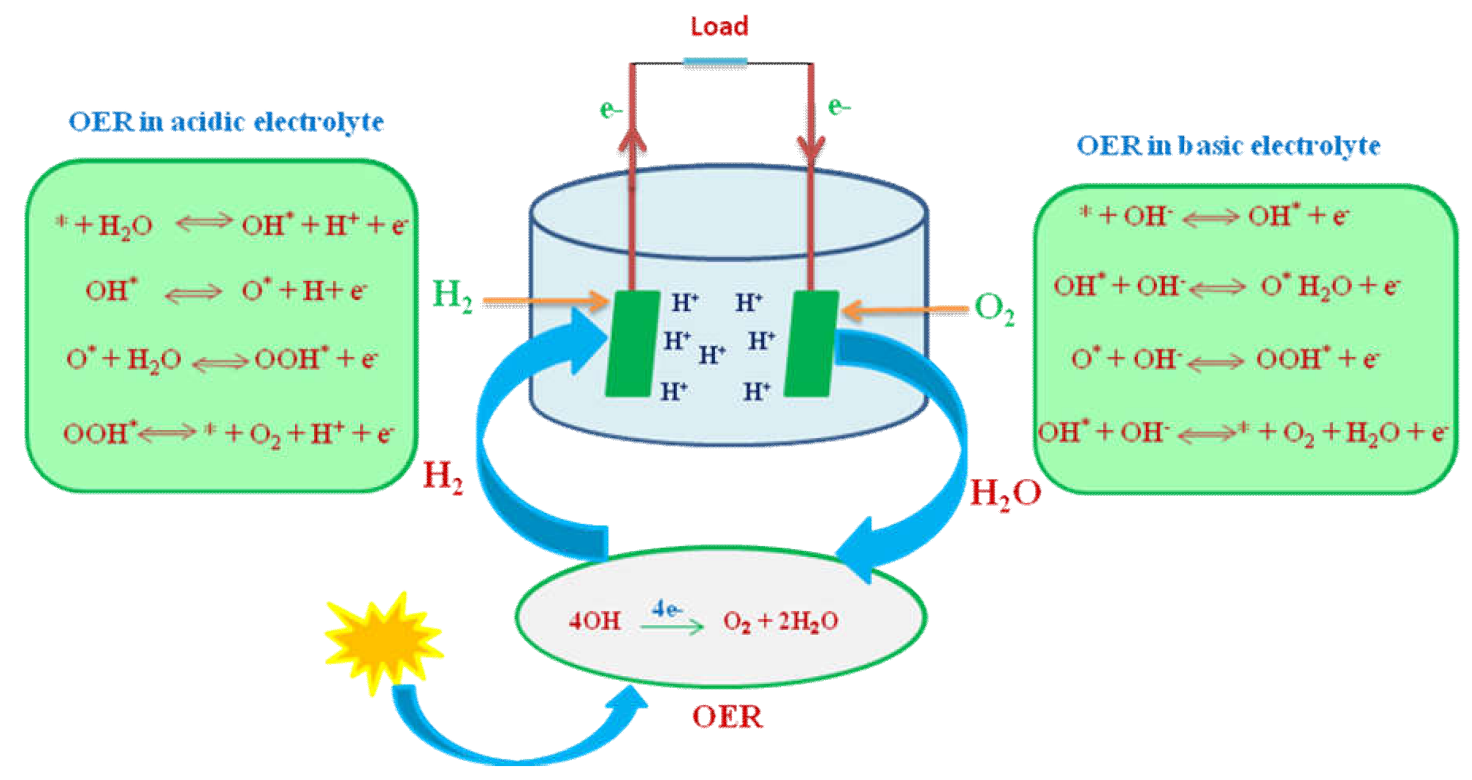

Scheme 1. Schematic representation of oxygen evolution reaction (OER) by water hydrolysis (the activated molecules is denoted by the symbol * in the above scheme).

\section{Electrode Surface Area}

Electrode surface area is an important parameter to expose more electroactive sites and boost their electrocatalytic properties. $\mathrm{N}_{2}$ adsorption/desorption studies, the pore size distribution and thenumber of available electroactive sites have been estimated by the Brunauer-Emmett-Teller (BET) and Barrett-Joyner-Halenda methods [23,24]. The porous structure of $\mathrm{MoS}_{2}$ has been synthesized by the hydrothermal method. Due to the largespecific surface area $\left(17.5 \mathrm{~m}^{2} \mathrm{~g}^{-1}\right)$, the catalyst represents a promising candidate for OER activity with enhanced cyclic stability [25]. Sharma et al. [26] used $\mathrm{Co}_{3} \mathrm{O}_{4}$ with fascinating morphologies of hierarchical nanosheets to have a better particle size and large surface area $\left(37 \mathrm{~m}^{2} \mathrm{~g}^{-1}\right)$, whichresulted in next-generation supercapacitor $\left(\sim 230 \mathrm{~F} \mathrm{~g}^{-1}\right)$ energy storage device applications. The bi-functional natured CoP/HNCNP@CoP electrode matrix has been well established under certain conditions. The porous structured matrix has been analyzed by the $\mathrm{N}_{2}$ adsorption/desorption technique, and the estimated surface area value $\left(156.04 \mathrm{~m}^{2} \mathrm{~g}^{-1}\right)$ has been confirmed by the BET method and it could provide benefits for the energy conversion process [27]. The Ru-doped $\alpha-\mathrm{MnO}_{2}$-based benchmark electrocatalysts were shown to be an excellent catalyst for OER, with a larger BET surface area $\left(87.4 \mathrm{~m}^{2} \mathrm{~g}^{-1}\right)$. This is clearly indicated by the size and shape of the particles. Furthermore, the most attractive bi-functional Ru-doped $\alpha-\mathrm{MnO}_{2}$ catalyst could also be used for water splitting reactions [28] The 3D-conductive flake structure of ironbased nitrogen and nanocarbon-derived (Fe-NSDC) electrocatalysts shows a large surface area $\left(1533.7 \mathrm{~m}^{2} \mathrm{~g}^{-1}\right)$ with high microporous structure volume $\left(0.39 \mathrm{~cm}^{3} \mathrm{~g}^{-1}\right)$, and aresulting current density value of $100 \mathrm{~mA} \mathrm{~cm}^{-2}$ for a Zn-air battery [29]. Wahab et al. [30] developed a low-cost, metal-free and high surface area $\left(406 \mathrm{~m}^{2} \mathrm{~g}^{-1}\right)$ mesoporous-based graphitic carbon nitrite (gMesoCN) catalyst that showed good electrochemical performance for OER in alkaline conditions. Very recently, Zhang et al. [31] designed and synthesized a novel $\mathrm{Co}_{9} \mathrm{~S}_{8}$ and $\mathrm{MoS}_{2}$ nanocrystal-modified 3D nitrogen-doped carbon nanoflakes ( $\left.\mathrm{Co}_{9} \mathrm{~S}_{8}-\mathrm{MoS}_{2} / \mathrm{N}-\mathrm{CNAs} @ \mathrm{CNFs}\right)$ catalyst (Figure 1), which shows a high electrode surface area $\left(178.46 \mathrm{~m}^{2} \mathrm{~g}^{-1}\right)$; thereby it has more active sites and can act with good electrocatalytic activity towards OER. The state-of-the-art cobalt-supported nitrogen codoped 3D graphene (Co-N-G) nanospheres have drawn special attention due to the large BET surface area $\left(365.2 \mathrm{~m}^{2} \mathrm{~g}^{-1}\right)$ determined from the $\mathrm{N}_{2}$ adsorption/desorption method and having an effective electrocatalyst performance in OER (Figure 2a,b) [32]. A class of ordered mesoporous-structured carbon-supported $\mathrm{Co}_{3} \mathrm{O}_{4}$ has been successfully synthesized 
by a soft-templating method. Herein, poly (ethylene oxide)-b-polystyrene can be used as a synthetic agent. In addition, the $\mathrm{Co}_{3} \mathrm{O}_{4}$ catalyst can act with superior electrocatalytic properties due to havingversatile properties like controlled morphologies, a larger BET electrode surface area $\left(407 \mathrm{~m}^{2} \mathrm{~g}^{-1}\right)$, along with higher OER catalytic activity [33].

(a)

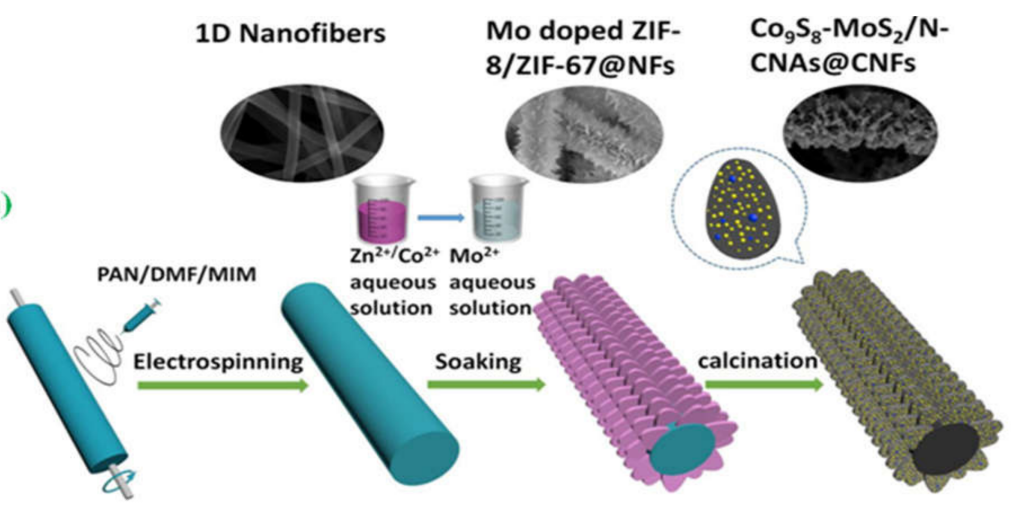

(b)

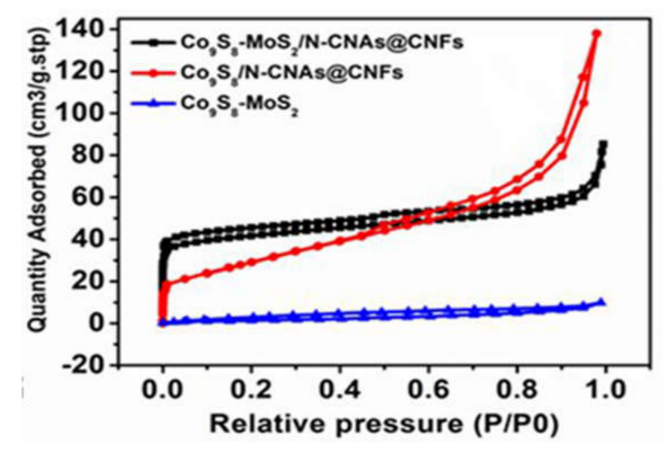

Figure 1. (a) Schematic illustration of the synthesis scheme of $\mathrm{Co}_{9} \mathrm{~S}_{8}-\mathrm{MoS}_{2} / \mathrm{NCNAs} @ \mathrm{CNFs}$ and (b) $\mathrm{N}_{2}$ adsorption/desorption isotherms of samples. Copyright 2020 by the American Chemical Society [31].
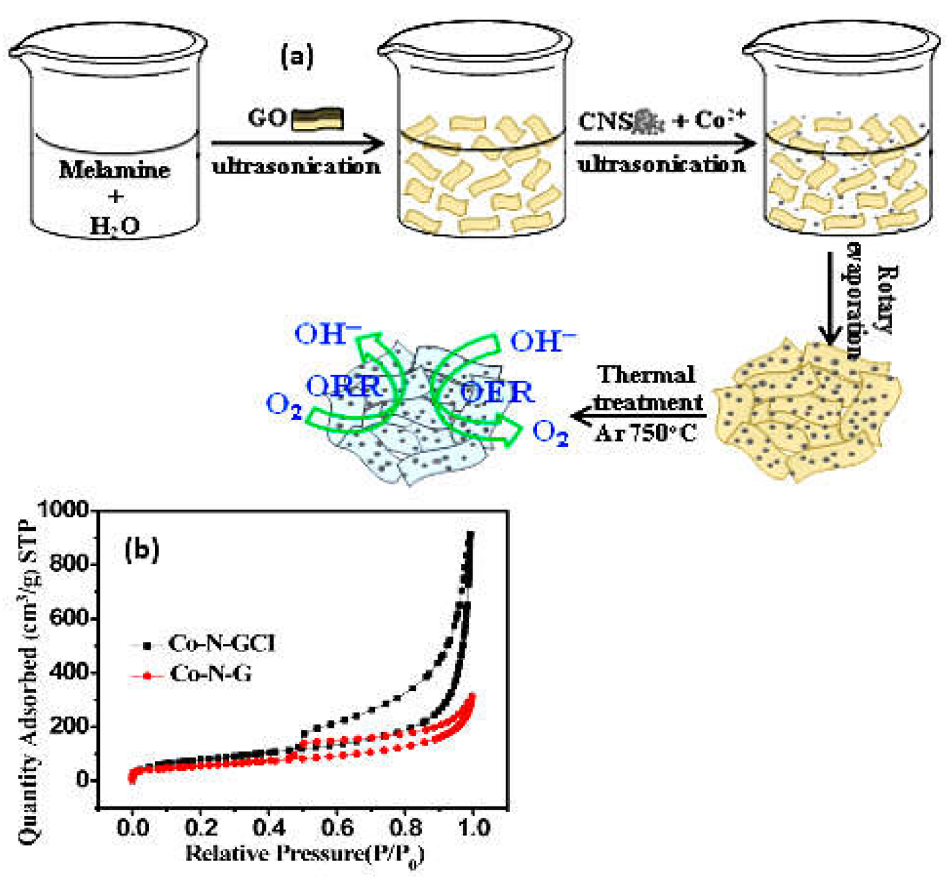

Figure 2. (a) Schematic illustration of the fabrication process for the Co-N-G catalyst along with effective catalytic performance towards OER and (b) nitrogenadsorption/desorption isotherms. Copyright 2016 by the American Chemical Society [32]. 


\section{Advanced Electrode Materials for OER}

The major classes of electrode materials fabricated and successfully used for OER applications in the literature are related to metal oxides, polymer composites, porous carbon, conducting polymers, metal and carbon-based nanoparticles, graphene and carbon nanotubes [34]. In this section, we focused on the recent development of new electrode materials used for the generation of $\mathrm{O}_{2}$ through the electrochemical oxidation of water in energy applications.

\subsection{Nanocarbon-Based Electrodes}

$\mathrm{NiCO}_{2} \mathrm{O}_{4}(\mathrm{NC})$-carbon dots (CDs) nano needle arrays have been fabricated on nickel (Ni) foam and directly used as an OER catalyst without any electrode binder [35]. Poly(vinyl pyrrolidone) were exposed to heat for $5 \mathrm{~h}$ at $180^{\circ} \mathrm{C}$ to obtain $\mathrm{CDs}$, and then different amount $(5,25$ and $40 \mathrm{mg}$ ) of CDs were mixed with another couple of salts to generate the catalysts, and they were denoted as NCCD5, NCCD25 and NCCD40, respectively. The developed materials were applied for OER activity in alkaline media $(1 \mathrm{M} \mathrm{KOH})$ and it was found that NC, NCCD5, NCCD25 and NCCD40 exhibited the onset potential of $510,460,390$ and $470 \mathrm{mV}$ vs. RHE, respectively. It is clear that the catalytic response significantly improved upon the incorporation of CDs into the NC. However, the onset potential increased upon loading a higher concentration of CDs ( $40 \mathrm{mg}$ ) due to the excessive number of CDs, which induced aggregation. Further, the Tafel slope of the catalysts was examined to be 140,95 and $165 \mathrm{mV} \mathrm{dec}^{-1}$ for NCCD5, NCCD25 and NCCD40, respectively, and this indicates that a more effective electron transfer occurs in NCCD25 than the other two materials. For practical applicability, the electrochemical durability of the materials was evaluated by continuous run the potential window between 1.1 to $1.9 \mathrm{~V}$ vs. RHE for 1000 cycles. NCCD25 displayed stable OER performances of about $>98.5 \%$, whereas NC maintained $\sim 95 \%$ retention of the initial potential. These results supported that the developed hierarchical NCCD nanohybrid provides a higher chargetransfer rate along with improved electrocatalytic performances and stability owing to the presence of a larger number of active sites.

A bifunctional electrode material for OER was reported based on carbon nanosheetdecorated nickel oxide $(\mathrm{NiO})$, and it appears as a rambutan-like hollow carbon sphere, as shown in Figure 3 [36]. A simple hydrothermal method was used to generate the hollow-structured precursor, and next, the precursor was calcinated under the anaerobic condition at $320^{\circ} \mathrm{C}$ for $2 \mathrm{~h}$. Finally, $\mathrm{NiO}$ nanoparticle-decorated hollow carbon nanosheets $(h-\mathrm{NiO} / \mathrm{C})$ with the size of $2 \mathrm{~nm}$ were obtained. The catalytic efficiency of $h-\mathrm{NiO} / \mathrm{C}$ was evaluated in $1 \mathrm{M} \mathrm{KOH}$ and the performances were compared with its precursor $h-\mathrm{NiO}$ and the commercial catalyst $\mathrm{RuO}_{2}$. An overpotential of $260 \mathrm{mV}$ was achieved at $10 \mathrm{~mA} \mathrm{~cm}{ }^{-2}$ for the $h-\mathrm{NiO} / \mathrm{C}$ electrode, which is significantly lower than the overpotential obtained for $h$-NiO (302 mV). Moreover, a smaller Tafel slope of $37.6 \mathrm{mV} \mathrm{dec}^{-1}$ was obtained for the $h-\mathrm{NiO} / \mathrm{C}$ electrode compared to $h-\mathrm{NiO}\left(72.5 \mathrm{mV} \mathrm{dec}^{-1}\right)$ and $\mathrm{RuO}_{2}\left(115.3 \mathrm{mV} \mathrm{dec}^{-1}\right)$. This faster electrode kinetics imply that the synergistic effect between oxygen vacancies and the carbon framework could improve the OER performances.

\subsection{Porous Carbon and Metal-Based Electrodes}

Zhang and coworkers developed a 3D Ni foam/porous carbon/anodized Ni (NF/PC/AN) electrode for OER application. The fabrication of composite materials was carried out by a step-by-step process [37]. Firstly, to enhance the affinity of Ni foam, the oxide layer was removed by the acidified polyvinylpyrrolidone. Subsequently, Ni foam was soaked into the mixture of zinc nitrate and 2-methylimidazole (ZIF-8) and deposited on the polyhedral crystal membrane with a thickness of $4.5 \mu \mathrm{m}$. The resulting material underwenta calcinations process at $800{ }^{\circ} \mathrm{C}$ for $5 \mathrm{~h}$ to convert it into Ni foam/porous carbon. Finally, anodization was performed at a constant applied potential of $1 \mathrm{~V}$ vs. $\mathrm{Ag} / \mathrm{AgCl}$ in $0.1 \mathrm{M}$ $\mathrm{KOH}$ for $2 \mathrm{~h}$ to attain the 3D NF/PC/AN electrode material. The as-prepared material was tested to the OER activity. The 3D NF/PC/AN electrode showed a weak anodic 
and cathodic wave at 470 and $445 \mathrm{mV}$ attributed to the $\mathrm{Ni}(\mathrm{OH})_{2} / \mathrm{NiOOH}$ redox reaction. Further, a pronounced catalytic wave emerged with an onset potential of $560 \mathrm{mV}$. The observed catalytic response was significantly higher than the $\mathrm{Ni}$ foam electrode. The authors mentioned that the porous carbon membrane acts as an interlayer between the active surface and conductive substrate for efficient electron transport to promote the OER activity.

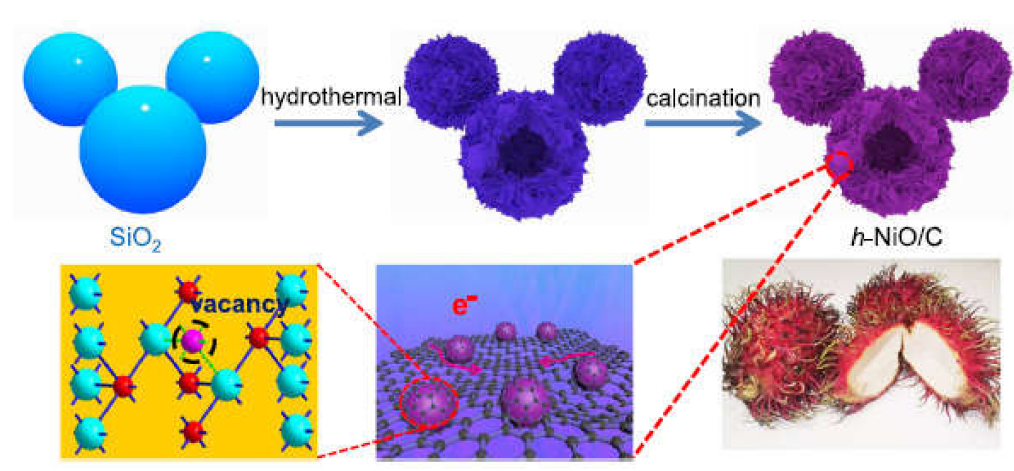

Figure 3. The fabrication process of $h-\mathrm{NiO} / \mathrm{C}$. The as-prepared $h-\mathrm{NiO} / \mathrm{C}$ sample with abundant oxygen vacancies looks like a rambutan shell. Inset: a photo of rambutans. Copyright 2019 by Wenzhou University and John Eiley andSons Australia, Ltd. [36].

As reported, the CoMoN $x$ is thermodynamically unstable and easily oxidized to form electroactive $\mathrm{CoMoO} x$ at a higher potential. Thus, $\mathrm{CoMoN} x$ nanosheets are vertically aligned on NP-Au, and it becomes largely accessible for the catalytic reaction. The fabricated catalyst assessed the OER capability and the catalytic response compared with its precursor coated electrodes such as $\mathrm{Au} / \mathrm{CoMoO}_{4}$ and $\mathrm{Au} / \mathrm{CoNx}$, and also the commercial catalyst $\mathrm{Au} / \mathrm{RuO}_{2}$. To check the importance of nanoporous $\mathrm{Au}$, the CoMoNx was coated on a glassy carbon electrode using a Nafion polymer binder.

As shown in Figure 4a, NP-Au/CoMoN $x$ exhibited a remarkable catalytic response compared to all other electrode materials. In addition, NP-Au/CoMoNx achieved a low

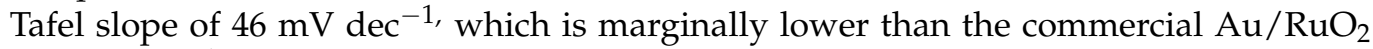
$\left(47 \mathrm{mV} \mathrm{dec}^{-1}\right)$ (Figure $\left.4 \mathrm{~b}\right)$. These superior catalytic performances are associated with the fast electron transfer of highly conductive CoMoNx [38] The durability of the NP$\mathrm{Au} / \mathrm{CoMoN} x$ electrode was evaluated by measuring continuously for $50 \mathrm{~h}$ at the current densities of 10 and $50 \mathrm{~mA} \mathrm{~cm}^{-2}$, and it was found that the overpotential remained stable at $10 \mathrm{~mA} \mathrm{~cm}^{-2}$, whereas the overpotential slightly increased at $50 \mathrm{~mA} \mathrm{~cm}^{-2}$ as a result of the decreasing aqueous electrolyte concentration.

Very recently, Kumar et al., reported a coral-shaped $\mathrm{NiCo}_{2} \mathrm{O}_{4}$ nanostructure catalyst for bi-functional activities [39]. Interestingly, the coral-shaped nanostructure was developed by growing less stable and highly reactive (111) planes of $\mathrm{NiCo}_{2} \mathrm{O}_{4}$ single crystals (32 to $35 \mathrm{~nm}$ ) at the (100) planes in the $\langle 111\rangle$ direction to minimize the total interfacial free energy and thereby get attached to each other and form a chain-like nanostructure. The authors mentioned that the aging process plays a vital role in catalytic performances of the catalyst due to the increase of the particle and agglomeration size of the nanostructure.

Based on varying the aging time between 6 and $24 \mathrm{~h}$, several samples were prepared and they were denoted as NCO6, NCO12, NCO18 and NCO24 for 6 h, 12 h, 18 h and $24 \mathrm{~h}$ of aging time, respectively. The developed electrode materials were tested for OER activity in $0.1 \mathrm{M} \mathrm{KOH}$. Among the various aging times, the material prepared at $24 \mathrm{~h}(\mathrm{NCO} 24)$ exhibited a superior catalytic response due to its highly porous coral-shaped nature, and this catalytic activity was compared with the commercial catalyst $\mathrm{IrO}_{2}$. NCO24 displayed $30 \mathrm{mV}$ onset potential and $290 \mathrm{mV}$ overpotential at $10 \mathrm{~mA} / \mathrm{cm}^{2}$ current density for OER compared to $\mathrm{IrO}_{2}$, which offers $310 \mathrm{mV}$. Additionally, the Tafel slope of $102 \mathrm{mV} / \mathrm{dec}$ was estimated for NCO24, which is comparable with the value obtained for the $\mathrm{IrO}_{2}$ sample (97 $\mathrm{mV} / \mathrm{dec})$. 

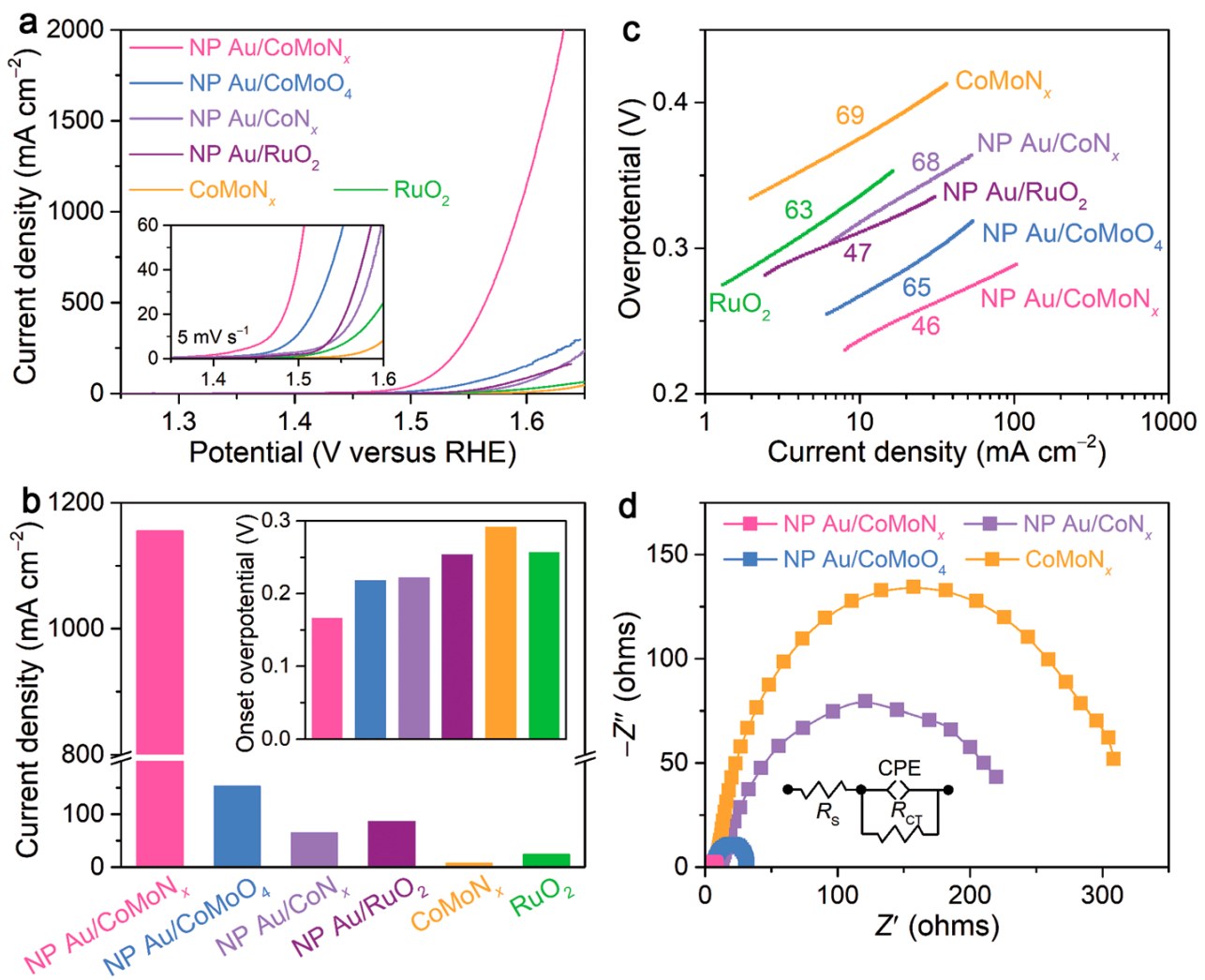

Figure 4. OER activity of bimetallic cobalt-molybdenum nitride nanosheets vertically aligned on $\mathrm{NP}-\mathrm{Au}$ electrodes in alkaline media. (a) OER polarization curves of NP-Au/CoMoNx, $\mathrm{Au} / \mathrm{CoMoO}_{4}$, $\mathrm{Au} / \mathrm{CoN} x$ and $\mathrm{Au} / \mathrm{RuO}_{2}$, as well as free CoMoNx nanosheets and $\mathrm{RuO}_{2}$ immobilized on a GC electrode at $5 \mathrm{mV} \mathrm{s}^{-1}$ in $1 \mathrm{M} \mathrm{KOH}$. Inset: Expanded view of the lowoverpotential region in panel (b). Comparison of the current densities at the overpotential of $0.37 \mathrm{~V}$ for the electrodes shown in panel (a). Inset: The onset overpotentials of these different electrocatalysts for the OER. (c) Tafel plots comparing the Tafel slopes of different catalysts obtained from the polarization curves in panel (a). (d) EIS spectra of electrodes shown in panel (a). Copyright 2020 by John Wiley and Sons [38].

The solvothermal process was employed to design the mesoporous CoFe-based nanomaterials for OER activity [40]. The OER performance was examined by the varying pore size of materials. Basically, two mesoporous materials with different pore sizes were developed by the incorporation of surfactants, namely hexadecyltrimethylammonium bromide (CTAB) and polyethylene glycol 4000 (PEG-4000), and the constructed materials were referred to as CFO@C-1 and CFO@C-2, respectively. It was revealed that CFO@C-1 has more pores than CFO@C-2. The average pore size was found to be $29.3 \mathrm{~nm}$ and $10.1 \mathrm{~nm}$ for CFO@C-1 and CFO@C-2, respectively. The catalytic performance of the electrode materials was investigated and compared with the monometallic counterparts (CO@C-1 and FO@C-1)and also to the commercial catalyst $\mathrm{RuO}_{2}$. As shown in Figure 5,CFO@C-1 exhibits better catalytic activity compared with CFO@C-2, CO@C-1, FO@C-1 and $\mathrm{RuO}_{2}$. CFO@C-1 showed the overpotential of $248 \mathrm{mV}$ at $10 \mathrm{~mA} \cdot \mathrm{cm}^{-2}$ for OER compared to CFO@C-2 (265 mV), CO@C-1 (338 mV), FO@C-1 (400 mV) and RuO $(324 \mathrm{mV})$. In addition, CFO@C-1 exhibited a lower Tafel slope of $58.7 \mathrm{mV} \cdot \mathrm{dec}^{-1}$ compared to CFO@C-2 (85.3 mV dec $\left.{ }^{-1}\right)$, CO@C-1 (75.9 mV dec $\left.{ }^{-1}\right)$, FO@C-1 (108.7 mV dec $\left.{ }^{-1}\right)$ and $\mathrm{RuO}_{2}\left(97.1 \mathrm{mV} \mathrm{dec}{ }^{-1}\right)$. These results clearly indicate that CFO@C-1 has much faster OER kinetics and more superior catalytic activity due to the presence of a higher number of pore sizes. 

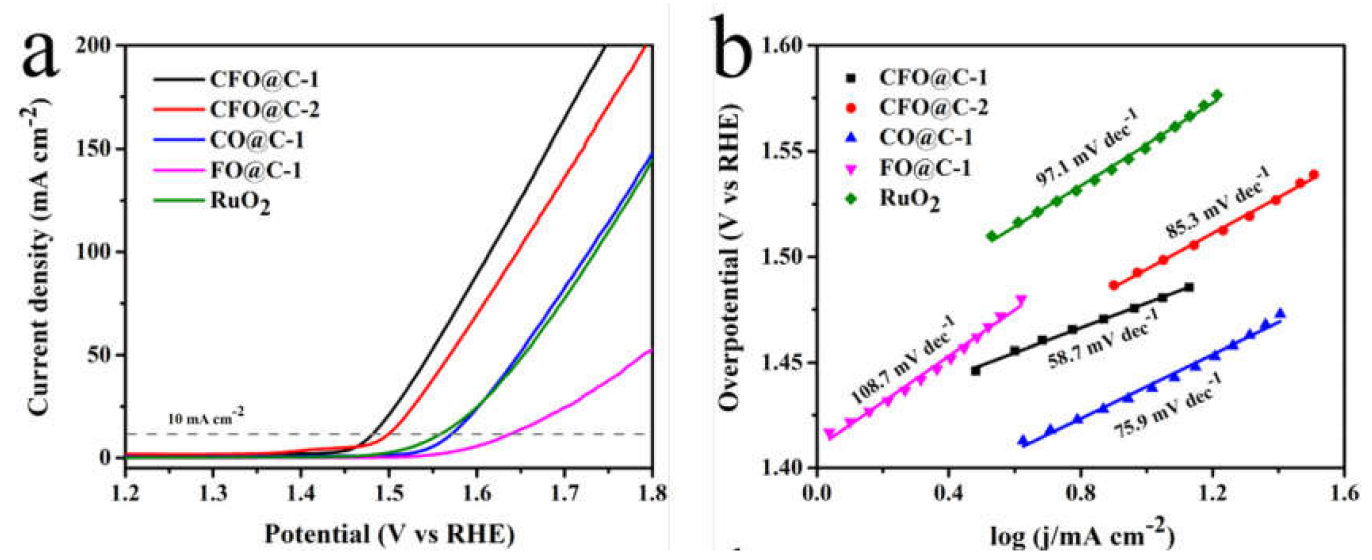

Figure 5. OER activity of mesoporous CoFe-based nanomaterials in $0.1 \mathrm{M} \mathrm{KOH}$. (a) LSV curves and (b) Tafel slopes for CFO@C-1, CFO@C-2, CO@C-1, FO@C-1 and RuO2. Copyright 2020 by Elsevier [40].

Chen and coworkers constructed a metal phosphide-based electrode material for OER activity [41]. A porous carbon membrane was prepared from Magnolia leaves and then used for the attachment of Fe-Co-P. The coating of Fe-Co-P on porous carbon was performed by electrochemical deposition, and this strong coupling promotes the stable electron and ion transport for OER. In addition, the pubescence fiber present in the Magnolia leaves can help to achieve efficient electron transport. OER activity was investigated for the prepared electrode material Fe-Co-P/C and also for its precursors, such as Fe-P/C and $\mathrm{Co}-\mathrm{P} / \mathrm{C}$, in $1 \mathrm{M} \mathrm{KOH}$. A pronounced OER catalytic response was achieved at Fe-Co-P/C, and it showed the overpotential of $151 \mathrm{mV}$ at $10 \mathrm{~mA} \mathrm{~cm}{ }^{-2}$. On the other hand, the overpotentials of $218 \mathrm{mV}, 186 \mathrm{mV}$ and $270 \mathrm{mV}$ were achieved at Fe-P/C, Co-P/C and pristine porous carbon, respectively. Moreover, Fe-Co-P/C displayed the Tafel slope of $77.78 \mathrm{mV} \mathrm{dec}^{-1}$, which was significantly smaller than Fe-P/C (88.24 mV dec $\left.{ }^{-1}\right)$ and Co$\mathrm{P} / \mathrm{C}\left(104.22 \mathrm{mV} \mathrm{dec}^{-1}\right)$. These results revealed the strong interaction between the porous carbon membrane and bimetallic phosphides, as well as the coupling effect between the Co and Fe elements, which remarkably increased the active sites.

\section{Functionalized Electrode Materials for OER}

The functionalization surface could modify the chemistry of the electrode material surface to provide specific properties related to the specified applications. Various functionalization methods employed in the literature as well as the primary outcomes of this process change the materials' surface energy. This modification can help for better coupling with other targeted substances at the molecular level [42-44]. Nowadays, the functionalization process is an unavoidable step at the basis of the preparation of efficient electrode materials. This section focuses on the electrode materials designed for OER applications related to functionalization with the polymer nanocomposite and doping of metals and non-metals.

\subsection{Nanocomposite-Based Electrodes}

Manganese oxide-integrated carbon $(\mathrm{MnO} / \mathrm{C})$ nanorod arrays were synthesized from Mn-metal-organic frameworks (MOFs) nanoarrays [45]. The hydrothermal method was utilized to grow Mn-MOF-74 nanorod array precursors directly on Ni foam substrate by the reaction of 2,5-dihydroxyterephthalic acid and manganese chloride tetrahydrate. Then, the annealing proceeds to sublimate the organic linker convert as a $\mathrm{MnO}$ nanorod array without any carbon component, which is denoted as $\mathrm{MnO} / \mathrm{C}$.In the calcination process, the temperature varied from $300{ }^{\circ} \mathrm{C}$ to $900{ }^{\circ} \mathrm{C}$ to convert Mn-MOF-74 into $\mathrm{MnO} / \mathrm{C}$ and, therefore, the obtained materials were referred to as MnO/C-300/350/450/550/650/750, respectively. The developed materials were successfully applied for OER application. Overall, the $\mathrm{MnO} / \mathrm{C}-\mathrm{T}$ materials displayed a better performance compared to the pure $\mathrm{MnO}$ electrode. Particularly, $\mathrm{MnO} / \mathrm{C}-350$ exhibited the superior OER response along with 
a low overpotential $\left(368 \mathrm{mV}\right.$ ) at the current density of $20 \mathrm{~mA} \mathrm{~cm}{ }^{-2}$ compared to the other $\mathrm{MnO} / \mathrm{C}-\mathrm{T}$ electrodes. Additionally, the catalytic response of $\mathrm{MnO} / \mathrm{C}-350$ compared with the commercial $\mathrm{IrO}_{2}$ achieved the overpotential of $481 \mathrm{mV}$.

An electrochemical method was performed to fabricate the nanocomposite electrode materials for OER application insitu based on $\mathrm{NiO}$ nanoparticles entrapped in a polypyrrole matrix. The preparation protocol is given in Figure 6 [46]. Firstly, the cationic poly(pyrroleammonium) film (poly1) was electrochemically deposited with an applied potential of +0.95 vs. $\mathrm{Ag} / \mathrm{AgNO}_{3}$ on carbon or an ITO electrode, and then, using the ion-exchange method, a $\mathrm{BF}_{4}{ }^{-}$counter ion was replaced with the anionic nickel oxalate complex, $\left[\mathrm{Ni}\left(\mathrm{C}_{2} \mathrm{O}_{4}\right)_{2}\right]^{2-}$. Subsequently, the nickel oxalate was converted into $\mathrm{Ni}^{0}$ nanoparticles by electrochemical reduction at an applied potential of $-1.4 \mathrm{~V}$ vs. $\mathrm{Ag} / \mathrm{AgCl}$. To compare the role of the poly1 film coating, $\mathrm{Ni}^{0}$ nanoparticles were deposited on the bare carbon electrode. The deposited film showed a well-defined redox response around $0.74 \mathrm{~V}$, corresponding to the $\mathrm{Ni}^{\mathrm{II}}(\mathrm{OH})_{2} / \mathrm{Ni}^{\mathrm{III}}(\mathrm{O})(\mathrm{OH})$ redox couple [47].

The catalytic performance of $\mathrm{C} /$ poly1- $\mathrm{NiO} x$ and $\mathrm{C} / \mathrm{NiO} x$ electrodes was examined for OER activity at $\mathrm{pH} 9.2,13$ and 14. Interestingly, the developed electrodes are catalytically active at $\mathrm{pH}$ 9.2, which is very important for use for natural water samples and also other applications like photoelectrochemical cells, where the molecular photosensitizer is often poorly stable in strongly basic solutions [48]. Further, the catalytic current drastically increased upon increasing the $\mathrm{pH}$ from 9.2 to 14 . Additionally, the overpotential decreased from 0.61 to $0.35 \mathrm{~V}$.

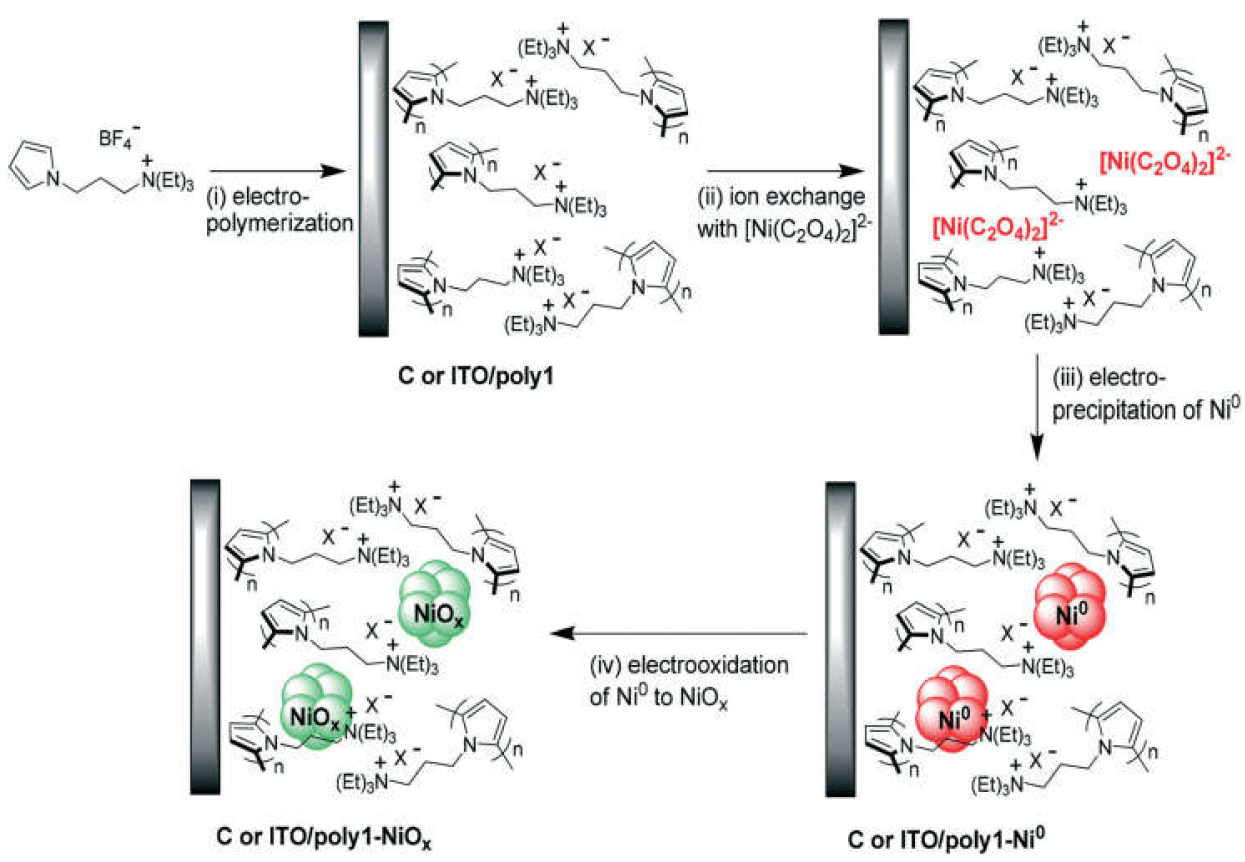

Figure 6. Electrosynthesis of poly(pyrrole-alkylammonium)/ $\mathrm{NiO} x$ composite film-modified electrodes. (i) Formation of poly1 by oxidative electro-polymerization of monomer $1(4 \mathrm{mM})$ at $\mathrm{E}_{\text {app }}=+0.95 \mathrm{~V}$ vs. $\mathrm{Ag} / \mathrm{AgNO}_{3}$ in $\mathrm{CH}_{3} \mathrm{CN}, 0.1 \mathrm{M}\left[\mathrm{Bu}_{4} \mathrm{~N} \mathrm{ClO}_{4}\right.$; (ii) incorporation of $\left[\mathrm{Ni}_{2}\left(\mathrm{C}_{2} \mathrm{O}_{4}\right)_{2}\right]^{2-}$ into poly1 upon soaking for $1 \mathrm{~h}$ in an aqueous solution (pH 6) of $1 \mathrm{mM} \mathrm{NiSO}_{4}, 5 \mathrm{mM} \mathrm{NaC}_{2} \mathrm{O}_{4}$, $0.1 \mathrm{M} \mathrm{Na}_{2} \mathrm{SO}_{4}$ and $0.1 \mathrm{M} \mathrm{H}_{3} \mathrm{BO}_{3}$; (iii) electro-precipitation of $\mathrm{Ni}^{0}$ within poly1 at $\mathrm{E}_{\mathrm{app}}=-1.4 \mathrm{~V}$ vs. $\mathrm{Ag} / \mathrm{AgCl}$ in the previously mentioned aqueous solution of nickel oxalate; (iv) electrooxidation of $\mathrm{Ni}^{0}$ to $\mathrm{NiO}_{\mathrm{x}}$ by repeated cyclic voltammetry scans between 0 and $+1.2 \mathrm{~V}$ vs. $\mathrm{Ag} / \mathrm{AgCl}$ in an aqueous solution ( $\mathrm{pH}$ 9.2) of $0.1 \mathrm{M} \mathrm{H}_{3} \mathrm{BO}_{3}$ and $0.05 \mathrm{M} \mathrm{NaOH}$. Copyright 2018 by Royal Society of Chemistry [46].

\subsection{Non-Metal-Doped Electrodes}

Nitrogen $(\mathrm{N})$ doping in carbon materials could increase the positive charge of adjacent carbon atoms due to its stronger electronegativity, promoting the OER activity by 
the strong interaction between the $\mathrm{OOH}$ and $\mathrm{N}$-doped site [49]. Zhang et al., employed the N-doping strategy to design the electrocatalyst N-doped spongy Ni (N-SN) for OER activity [50]. The as-prepared electrode material showed enhanced conductivity and an increased number of active sites, which offers remarkable OER performance. Further, N-SN achieved the low overpotential of $365 \mathrm{mV}$ at $100 \mathrm{~mA} \mathrm{~cm}^{-2}$ and a small Tafel slope of $33 \mathrm{mV} \mathrm{dec}^{-1}$, outperforming the unmodified sponge Ni electrode that showed the overpotential of $549 \mathrm{mV}$ with a Tafel slope of $40 \mathrm{mV} \mathrm{dec}{ }^{-1}$.Further, $\mathrm{N}$-doped carbon-functionalized $\mathrm{CoSe}_{2}$ nanowires (CoSe $\mathrm{C}_{2} @ \mathrm{~N}-\mathrm{C}$ NWs) were proposed for OER activity [51].The constructed $\mathrm{CoSe}_{2} @ \mathrm{~N}-\mathrm{C}$ NWs attained a 6.61-fold higher OER catalytic response compared to the pristine $\mathrm{CoSe}_{2} \mathrm{NW}$ electrode in $1.0 \mathrm{M} \mathrm{KOH}$ solution. This excellent catalytic response is attributed to the formation of an active $\mathrm{CoO}_{x} \mathrm{H}_{\mathrm{y}} / \mathrm{CoSe}_{2} @ \mathrm{~N}-\mathrm{C}$ NWs heterostructure. Based on the theoretical calculation, the authors pointed out that $\mathrm{N}$-doping is beneficial for the optimization of free energy. In more details, the conversion of $\mathrm{O}^{*}$ to $\mathrm{OOH}^{*}$ at the pristine $\mathrm{CoSe}_{2}$ electrode resulted in the uphill potential of $1.80 \mathrm{eV}$ with a high overpotential of $0.57 \mathrm{~V}$, whereas the potential significantly decreased to $1.63 \mathrm{eV}$ with a low overpotential of $0.40 \mathrm{~V}$ at $\mathrm{N}$-doped $\mathrm{CoSe}_{2} @ \mathrm{~N}-\mathrm{C}$ NWs.

Liu et al., constructed a hybrid electrocatalyst for OER application by the amalgamation of PtCo and N-doped carbon nanofiber (NCNF) [52]. The hybrid PtCo/NCNF comprises PtCo alloy nanoparticles (NPs) surrounded by a few N-doped carbon layers. The SEM images illustrate that PtCo alloy NPs exist with an average diameter of $8.9 \mathrm{~nm}$, and they are uniformly embedded in the carbon matrix. The hybrid material was tested towards catalytic performance for OER activity and the results were compared with other combinations of materials as well as the well-known commercial catalyst $\mathrm{Pt} / \mathrm{C}$, as depicted in Figure 7. The PtCo/NCNF catalyst showed the OER reaction at $1.64 \mathrm{~V}$ vs. RHE compared to the N-undoped PtCo/CNF $(1.74 \mathrm{~V})$, and this indicates that the $\mathrm{N}$ content tremendously enhanced the activity (Figure $7 \mathrm{a}$ ). All other materials exhibited a very poor catalytic response with anobserved potential around $1.9 \mathrm{~V}$.
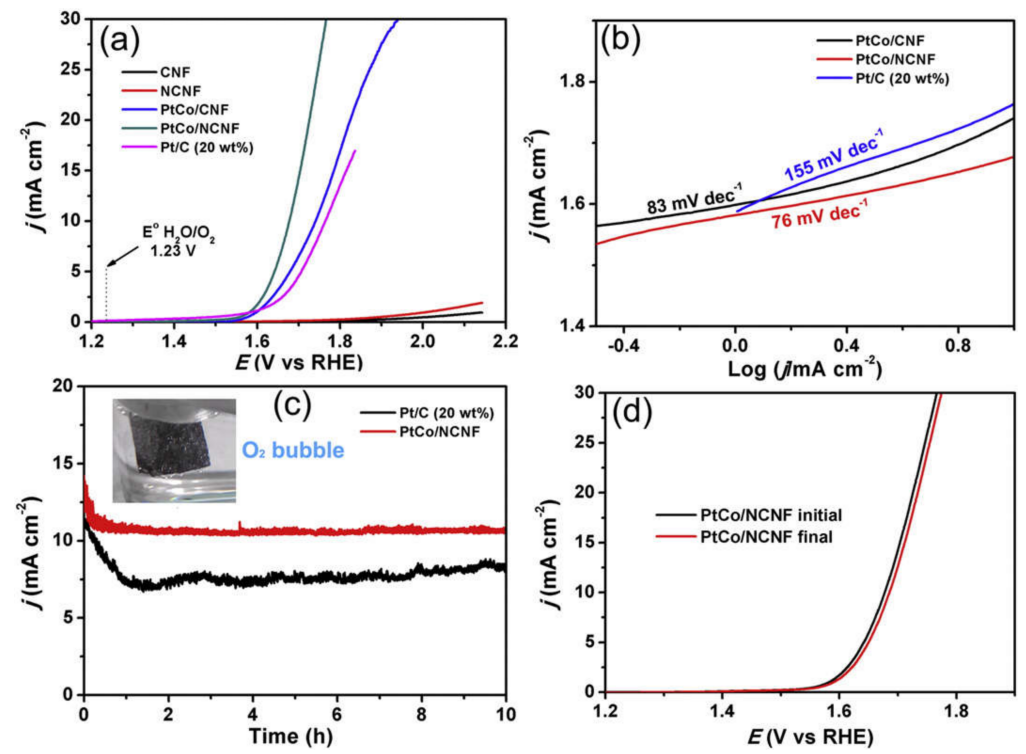

Figure 7. OER activity of a hybrid PtCo and N-doped carbon nanofiber catalyst in $1 \mathrm{M} \mathrm{KOH}$. (a) Polarization curves of CNF, NCNF, $\mathrm{PtCo} / \mathrm{CNF}$ and $\mathrm{PtCo} / \mathrm{NCNF}$, as well asPt/C catalyst (20 wt $\%$ ), at a potential sweep rate of $1 \mathrm{mV} \mathrm{s}^{-1}$. (b) Tafel plots of PtCo/CNF and PtCo/NCNF in $1 \mathrm{M} \mathrm{KOH}$ solution. (c) Chronoamperometric response (j-t) recorded on the $\mathrm{PtCo} / \mathrm{NCNF}$ and $\mathrm{Pt} / \mathrm{C}$ catalyst (20 $\mathrm{wt} \%$ ) membrane electrode at a constant applied potential of $1.64 \mathrm{~V}$ vs. RHE. The PtCo/NCNF catalyst was directly used as the working electrode. Inset in (c) is the optical image of the PtCo/NCNF membrane electrode operating at $1.64 \mathrm{~V}$ with generated $\mathrm{O}_{2}$ bubbles on the surface. (d) Polarization curves of the PtCo/NCNF membrane electrode before and after 1000 potential cycles (scan rate: $100 \mathrm{mV} \mathrm{s}^{-1}$ ). Copyright 2016 by Elsevier [52]. 
Further, the catalytic response of PtCo/NCNF was compared with the commercial $\mathrm{Pt} / \mathrm{C}$ and found that $\mathrm{PtCo} / \mathrm{NCNF}$ displayed $0.12 \mathrm{~V}$ lower potential than $\mathrm{Pt} / \mathrm{C}(1.76 \mathrm{~V})$. The electron transfer kinetics was investigated by the Tafel slopes and reported that 76, 83 and $155 \mathrm{mV} \mathrm{dec}{ }^{-1}$ were achieved for PtCo/NCNF, PtCo/CNF and Pt/C (20 wt\%), respectively (Figure 7b). This clearly specifies that the interaction between PtCo alloy NPs and the embedded $\mathrm{N}$-doped carbon layer plays a significant role in improving the electron transfer efficiency and catalytic response.The stability of PtCo/NCNF was investigated by applying a constant potential at $1.64 \mathrm{~V}$ in $1 \mathrm{M} \mathrm{KOH}$ for $10 \mathrm{~h}$ (Figure 7c). No significant difference was noted in the current density for PtCo/NCNF, whereas the commercial Pt/C catalyst dropped the current density after the continuous operation for $10 \mathrm{~h}$. Further, the durability of the PtCo/NCNF was evaluated by continuous cycling between 0 and $1.2 \mathrm{~V}$. As shown in Figure 7d, the current density decreased a negligible amount after 1000 cycles, and it confirms that $\mathrm{PtCo} / \mathrm{NCNF}$ has long-term viability under the operating conditions. The observed superior catalytic OER activity of PtCo/NCNF is associated with the synergistic effects of the small and well-dispersed carbon core-shell structures of the PtCo alloy and the high conductivity of N-doped CNF.

Boron (B) doping with nanomaterials is also considered an imperative method for developing efficient electrode materials for OER application. The boron is electrophilic and induces a positive charge on the neighboring $C$ atom when integrating with the carbon materials. It has been reported that the introduction of boron into graphene leads to develop of $\sigma$ bonds by three valence electrons of boron with three electrons of the $C$ atom from graphene [53]. Extra $\pi$-electrons present in the $C$ can create a deficiency of electrons in the conduction band and produce a p-type character in the valence band. A result of decreasing electron density in the boron is that it can directly increase the electron density of the neighboring active carbon, and this promotes the catalytic activity of B-doped materials [54]. Joshi et al., reported the fabrication of electrode materials for OER activity by the integration of $\mathrm{IrO}_{2}$ nanoparticles with B-doped reduced graphene oxide [55]. They demonstrated the effect of B-doping on the electronic structure modification of the $\mathrm{IrO}_{2}$ nanoparticles. When the doping of $\mathrm{B}$ was at $2 \mathrm{wt} \%$, the OER catalytic current density reached $28.6 \mathrm{~mA} \mathrm{~cm}^{-2}$ at $1.60 \mathrm{~V}$ for $\mathrm{IrO}_{2}$-B-rGO. The observed current density was almost 8 -fold higher than that of $\mathrm{B}$-free $\mathrm{IrO}_{2}-\mathrm{rGO}$. Additionally, the current density was 5 times higher in the B-doped electrode than pristine $\mathrm{IrO}_{2}$ powder.

Li et al., employed a hydrothermal-assisted biomimetic strategy to prepare the hybrid electrode material such as a $\mathrm{CoS}_{2}$ nanodot-embedded heteroatoms (nitrogen and sulphur)doped carbon layer $\left(\mathrm{CoS}_{2} @ H A D C\right)$ [56]. The catalyst was prepared by exposing the material at $200{ }^{\circ} \mathrm{C}$ for a different time frame. For instance, the catalysts obtained at 8,10 and $12 \mathrm{~h}$ are denoted as $\mathrm{CoS}_{2} @ \mathrm{HADC}-8$ h, $\mathrm{CoS}_{2} @ \mathrm{HADC}-10 \mathrm{~h}$ and $\mathrm{CoS}_{2} @ \mathrm{HADC}-12 \mathrm{~h}$, respectively. The catalytic performance towards OER was evaluated in $1 \mathrm{M} \mathrm{KOH}$. All hybrid catalysts exhibited an improved catalytic response compared to the individual counterpart $\operatorname{CoS}_{2}$. As reported, the optimized hybrid $\mathrm{CoS}_{2} @ \mathrm{HADC}-10$ showed the lowest overpotential of $226 \mathrm{mV}$ at $10 \mathrm{~mA} / \mathrm{cm}^{2}$, compared to the $\mathrm{CoS}_{2}$ (256 mV vs. RHE), $\mathrm{CoS}_{2} @ H A D C-8 \mathrm{~h}(236 \mathrm{mV})$ and $\mathrm{CoS}_{2} @ \mathrm{HADC}-12 \mathrm{~h}(236 \mathrm{mV})$. Additionally, the commercial catalyst $\mathrm{RuO}_{2}$ achieved the overpotential of $320 \mathrm{mV}$, which is about $94 \mathrm{mV}$ higher when compared to the $\mathrm{CoS}_{2} @ \mathrm{HADC}$ 10. Further, the Tafel slope value was calculated to be $56,93,75$ and $74 \mathrm{mV} \mathrm{dec}^{-1}$ for $\mathrm{CoS}_{2} @ \mathrm{HADC}-10, \mathrm{CoS}_{2}, \mathrm{CoS}_{2} @ \mathrm{HADC}-8 \mathrm{~h}$ and $\mathrm{CoS}_{2} @ \mathrm{HADC}-12 \mathrm{~h}$, respectively.

A bifunctional catalyst was developed for the OER and ORR based on B- and N-doped nanocarbon material [57]. The material was obtained by pyrolyzing the mixture of ethyl cellulose (EC) and 4-(1-naphthyl) benzene boronic acid (NBBA) in a $\mathrm{NH}_{3}$ atmosphere. To achieve a higher catalytic activity, carbon defects are generated by the decomposition of EC and $\mathrm{Zn}$-based templates containing oxygen species into $\mathrm{CO}_{x}$ and $\mathrm{H}_{2} \mathrm{O}$ by the graphitization process. The morphology of the nanocarbon composite was examined by the SEM, and it was found that it appeared as a nano sheet of a few hundred nanometers in size with a thickness of 20-30 nm. The fabricated material was successfully applied to the OER activity and also compared the catalytic performance with the conventional precious catalysts 
such as $\mathrm{RuO}_{2}$ and $\mathrm{Pt} / \mathrm{C}$. Figure 8, shows the onset potential of 1.57, 1.61 and $1.89 \mathrm{~V}$ vs. RHE obtained for B- and $\mathrm{N}$-doped carbon, $\mathrm{RuO}_{2}$ and $\mathrm{Pt} / \mathrm{C}$, respectively. It was clear that B- and N-doped carbon material exhibited a lower overpotential for OER activity than the other two commercial catalysts. Additionally, a similar ORR performance was achieved for B- and $\mathrm{N}$-doped carbon when compared to $\mathrm{Pt} / \mathrm{C}$. It was revealed that the higher catalytic response of $\mathrm{B}$ - and $\mathrm{N}$-doped carbon is associated with the presence of high-density carbon defects, which help to activate the graphitic $\pi$-electron system [58] along with the adsorption of oxygen species.
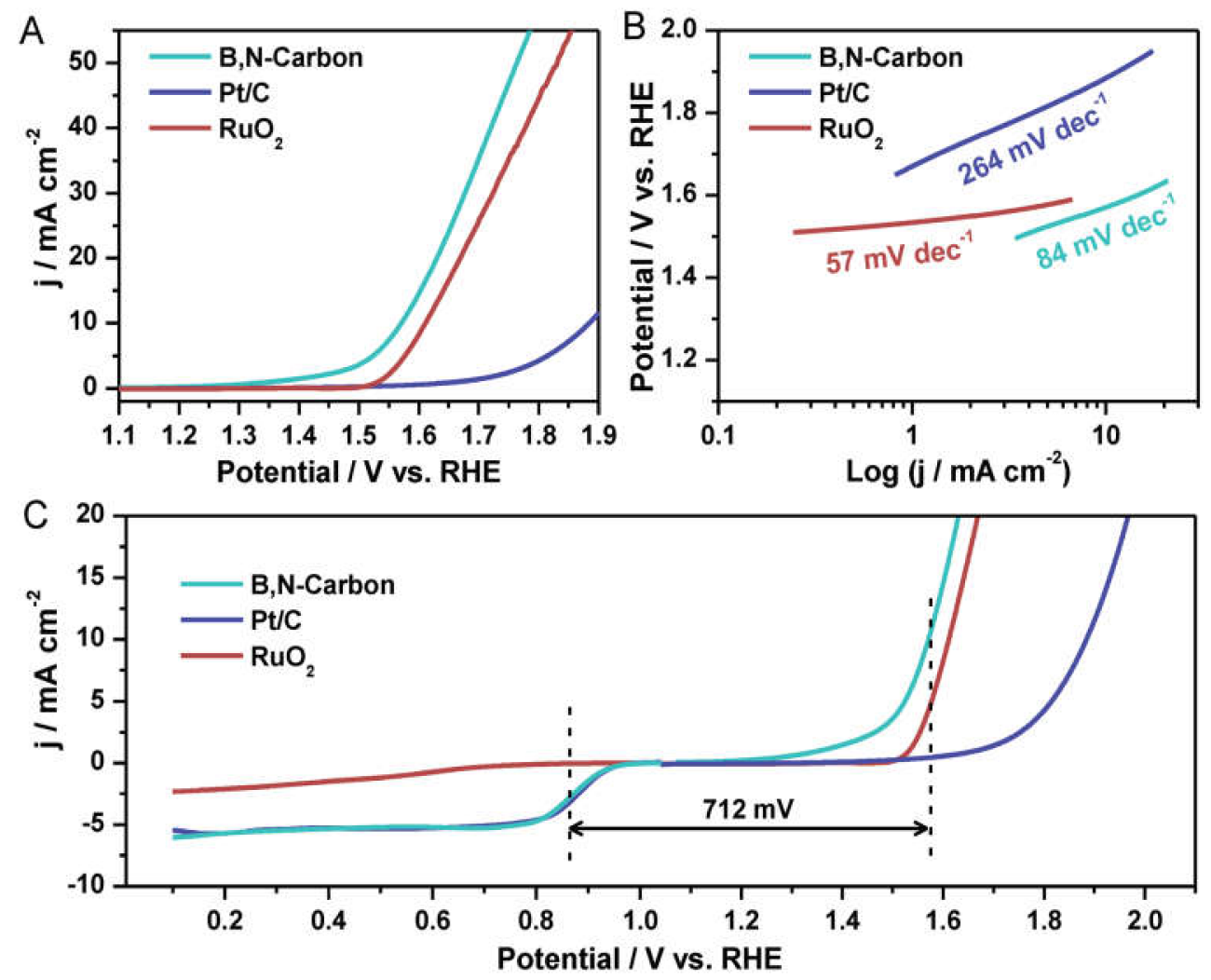

Figure 8. OER performances of the catalysts. (a) LSV curves measured at a rotation speed of $1600 \mathrm{rpm}$ with a scan rate of $5 \mathrm{mV} \mathrm{s}^{-1}$. (b) Tafel plots. (c) Bifunctional catalytic activities for ORR and OER in $\mathrm{O}_{2}$-saturated 1.0 M KOH. Copyright 2018 by Wiley-VCH Verlag GmbH \& Co. Weinheim [57].

\subsection{Metal-Doped Electrodes}

In general, transition metals are tremendously used as electrode materials for many applications [59-61]. This is because they are highly conductive due to the presence of multiple oxidation states, provide excellent redox properties and the proton is easily inserted or removed into the crystal lattice through the reduction-oxidation process. A binder-free electrode material was constructed based on copper $(\mathrm{Cu})$ and cobalt $(\mathrm{Co})$ co-doped $\mathrm{Ni}_{3} \mathrm{~S}_{2}\left(\mathrm{CuCo}-\mathrm{Ni}_{3} \mathrm{~S}_{2}\right)$ coated on $\mathrm{Ni}$ foam (NF) [62]. Simple hydrothermal and liquid-phase vulcanization methods were employed to directly deposit the $\mathrm{Ni}_{3} \mathrm{~S}_{2} \mathrm{NPs}$ on the NF surface, as illustrated in Figure 9. The catalytic activity of fabricated CuCo$\mathrm{Ni}_{3} \mathrm{~S}_{2} / \mathrm{NF}$ and its monometallic counterparts was investigated towards OER in $1 \mathrm{M} \mathrm{KOH}$. The catalytic response was also compared with commercial catalyst $\mathrm{RuO}_{2} / \mathrm{NF}$. A very poor catalytic response was observed for the bare NF electrode. On the other hand, a pronounced OER activity was recorded with $\mathrm{CuCo}-\mathrm{Ni}_{3} \mathrm{~S}_{2} / \mathrm{NF}$ and showed the overpotential of $400 \mathrm{mV}$ vs. RHE at a current density of $100 \mathrm{~mA} \mathrm{~cm}{ }^{-2}$. All other electrode materials, such as Co- $\mathrm{Ni}_{3} \mathrm{~S}_{2} / \mathrm{NF}, \mathrm{Cu}-\mathrm{Ni}_{3} \mathrm{~S}_{2} / \mathrm{NF}, \mathrm{Ni}_{3} \mathrm{~S}_{2} / \mathrm{NF}$ and $\mathrm{RuO}_{2} / \mathrm{NF}$, exhibited the overpotentials of $425 \mathrm{mV}, 430 \mathrm{mV}, 438 \mathrm{mV}$ and $460 \mathrm{mV}$, respectively. In addition to the OER catalytic peak, oxidation appeared at $1.4 \mathrm{~V}$, which was attributed to the $\mathrm{Ni}^{2+} / \mathrm{Ni}^{3+}$. Further, the activity of 
the catalyst was optimized based on the $\mathrm{Cu}$ to $\mathrm{Co}$ ratio and it was realized that the 1:1 ratio showed superior catalytic activity for OER. The observed superior catalytic performance of $\mathrm{CuCo}-\mathrm{Ni}_{3} \mathrm{~S}_{2}$ is due to co-doping of $\mathrm{Co}$ and $\mathrm{Cu}$ ions. It was mentioned that $\mathrm{Co}$ ion doping enhances the catalytic active sites, and $\mathrm{Cu}$ ion doping facilitates the charge transfer rate.

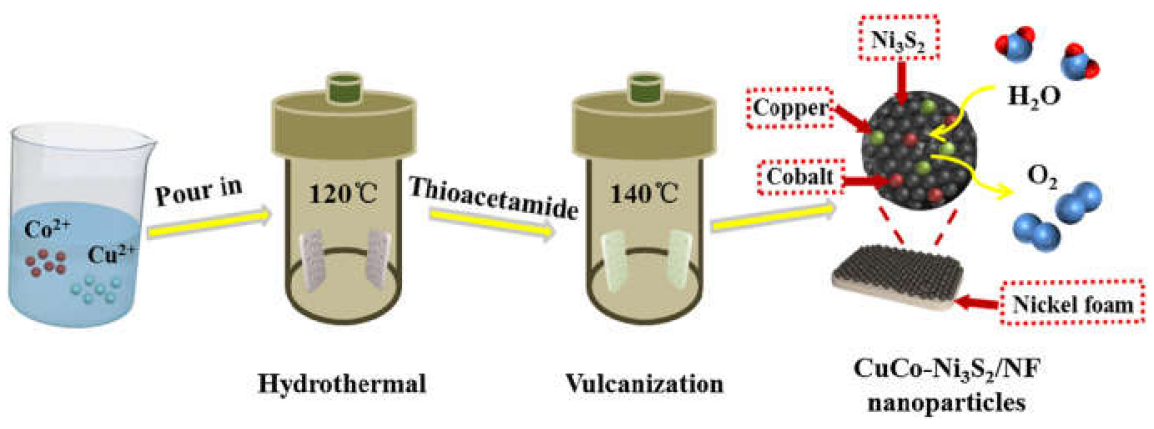

Figure 9. Fabrication processes of $\mathrm{CuCo}-\mathrm{Ni}_{3} \mathrm{~S}_{2}$ /NF. Copyright 2020 by Elsevier [62].

A monolithic electrocatalyst was designed for OER activity based on the electrodeposition of a rare-earth praseodymium-doped nickel-cobalt-iron hydroxide (NiFeCoPrO) onto a gold-deposited nickel foam (NF) substrate [63]. NiFeCoPrOAu/NF appeared in a size range between 2 and $80 \mathrm{~nm}$, with a peak volume of $\sim 3.5 \mathrm{~nm}$. Cyclic voltammetry was used to investigate the step-by-step incorporation of $\mathrm{Co}, \mathrm{Pr}$ and Au. The catalytic performance towards OER activity was examined in $3 \mathrm{M} \mathrm{KOH}$. NiFeCoPrOAu/NF showed a well-defined redox wave around $1.3 \mathrm{~V}$ vs. $\mathrm{RHE}$, corresponding to theNi ${ }^{2+} / \mathrm{Ni}^{3+}$ and $\mathrm{Co}^{3+} / \mathrm{Co}^{4+}$ redox couples [64]. The estimated overpotentials were 228, 247, 251, 260 and $393 \mathrm{mV}$ for $\mathrm{NiFeCoPrOAu} / \mathrm{NF}, \mathrm{NiFeCoPrO} / \mathrm{NF}, \mathrm{NiFeCoO} / \mathrm{NF}, \mathrm{NiFeO} / \mathrm{NF}$ and bare NF, respectively, at a current density of $60 \mathrm{~mA} \mathrm{~cm}^{-2}$. Among the electrode materials, the lowest onset potential was achieved at $\mathrm{NiFeCoPrO}-\mathrm{Au} / \mathrm{NF}$. These results supported that the incorporation of $\mathrm{Pr}$ and $\mathrm{Au}$ could remarkably increase the catalytic activities. A Tafel slope of $28 \mathrm{mV} \mathrm{dec}{ }^{-1}$ was obtained for the NiFeCoPrO-Au/NF electrode, which is significantly smaller than the commercial catalysts $\mathrm{RuO}_{2}\left(52.3 \mathrm{mV} \mathrm{dec}^{-1}\right)$ and $\mathrm{IrO}_{2}\left(63.1 \mathrm{mV} \mathrm{dec}^{-1}\right)$.

Transition metals, such as $\mathrm{Co}, \mathrm{Fe}, \mathrm{Mn}$ and Mo, were doped onto nickel phosphide NPbased electrode catalysts [65]. The as-prepared pristine and metal-doped nickel phosphide NP-coated GC electrodes were evaluated for OER performance in $1 \mathrm{M} \mathrm{KOH}$. The pristine nickel phosphide NPs exhibited the overpotential of $0.39 \mathrm{~V}$ vs. RHE at $20 \mathrm{~mA} \mathrm{~cm}^{-2}$. On the other hand, the transition metal-doped catalysts achieved the overpotential of $0.33,0.41,0.55$ and $0.43 \mathrm{~V}$ for FeCoP, NiCoP, NiMnP and NiMoP, respectively. Among the catalysts, FeCoP displayed a better catalytic response owing to providing an optimal bonding interaction with $\mathrm{M}-\mathrm{O}$ through the filling of antibonding and bonding bands.

Morever, a NiCoFe-layered double hydroxides catalyst was developed by the co-precipitation method for bifunctional activities such as ORR and OER. The catalytic performance of NiCoFe was evaluated by varying the Ni:Co:Fe ratios such as M1 (33\%Ni:33\%Co:34\%Fe), M2 (27\%Ni:40\%Co:33\%Fe) and M3 (47\%Ni:21\%Co:32\%Fe) [66].M3 exhibited the lowest onset potential, and the highest catalytic response among these ratios compared tothe other two catalysts, and the catalytic activity followed in the order M3 $<$ M1 < M2.These results revealed that the higher $\mathrm{Ni}$ content in the $\mathrm{M} 3$ promotes the synergy effect between the $\mathrm{NiO}$ amount and spinel-type structure.

\section{Water Splitting Electrolyzer for OER}

The energy essential for an indelible life is rising on a daily basis $[67,68]$. Hydrogen, which is well known as an environmentally benign energy carrier, has piqued the interest of researchers over the last few decades due to the fact that its oxidation product is only water [69-71]. Therefore, high hydrogen utilization as fuel, formed by artificial photosynthesis or electrolysis, can diminish the reliance on fossil fuels as well as the $\mathrm{CO}_{2}$ emission [72]. Consequently, water splitting is indeed one of the fundamental hydrogen 
manufacturing units for the aforesaid fuel consumption [73]. The water splitting is often based on two half-reactions: water oxidation and reduction, as shown below.

$$
\begin{gathered}
4 \mathrm{H}^{+}+4 \mathrm{e}^{-} \rightarrow 2 \mathrm{H}_{2} \mathrm{E}=(0-0.059 \mathrm{pH}) \mathrm{V} \text { vs. SHE } \\
2 \mathrm{H}_{2} \mathrm{O} \rightarrow \mathrm{O}_{2}+4 \mathrm{H}^{+}+4 \mathrm{e}^{-} \mathrm{E}=(1.23 \mathrm{~V}-0.059 \mathrm{pH}) \mathrm{V} \text { vs. SHE } \\
\text { Overall: } 2 \mathrm{H}_{2} \mathrm{O} \rightarrow 2 \mathrm{H}_{2}+\mathrm{O}_{2} \Delta \mathrm{E}=-1.23 \mathrm{~V} \text { vs. SHE }
\end{gathered}
$$

Four protons from the water molecule are removed, resulting in the formation of $\mathrm{O}=\mathrm{O}$ bonds during the water oxidation reaction, and at low potential, the activity of the water oxidation reaction is low, which is a significant hindrance for water splitting [74,75]. Numerous catalysts have been established to improve the water oxidation activity at a low potential. Due to their superior performance, noble metals are at the top of the list. Ni-based materials are promising electrocatalysts for the OER for water splitting in alkaline media. Gautam et al. synthesized various compositions of metallic and bimetallic Ni$\mathrm{Cu}$-nanostructured electrocatalysts for the OER. The Ni-Cu bimetallic nanoclusters of a specific molar ratio (52:48 mol\% Ni-Cu NSc) had an OER onset overpotential of $50 \mathrm{mV}$ and an overpotential of $150 \mathrm{mV}$ at $10 \mathrm{~mA} \mathrm{~cm}{ }^{2}$, making them the most effective nonprecious metal OER catalysts [76]. A simple solvothermal method was used to grow the NiSe/CFs catalyst. The prepared catalyst has excellent electrocatalytic activity and stability for OER in alkaline solutions. For instance, with a current density of $50 \mathrm{~mA} \mathrm{~cm}^{-2}$, the overpotential is $318 \mathrm{mV}$, and the Tafel slope achieved is $46 \mathrm{mV} \mathrm{dec}^{-1}$. At a current density of $20 \mathrm{~mA} \mathrm{~cm}^{-2}$ for $120 \mathrm{~h}$, a stable catalyst is formed. The electron transfer channel offered by an ordered nanowire structure and the enhanced catalytic sites afforded by NiSe have improved the OER catalytic performance. These noble metal-based electrocatalysts in alkaline solutions might be beneficial in the development of renewable energy sources [77]. Hou et al. [78] grew vertically aligned oxygenated- $\mathrm{CoS}_{2}-\mathrm{MoS}_{2}(\mathrm{O}-\mathrm{CoMoS})$ hetero-nanosheets on a flexible carbon fiber cloth using Anderson-type $\left(\mathrm{NH}_{4}\right)_{4}\left[\mathrm{Co}(\mathrm{II}) \mathrm{Mo}_{6} \mathrm{O}_{24} \mathrm{H}_{6}\right] 6 \mathrm{H}_{2} \mathrm{O}$ polyoxometalate as bimetal precursors (Figure 10a).
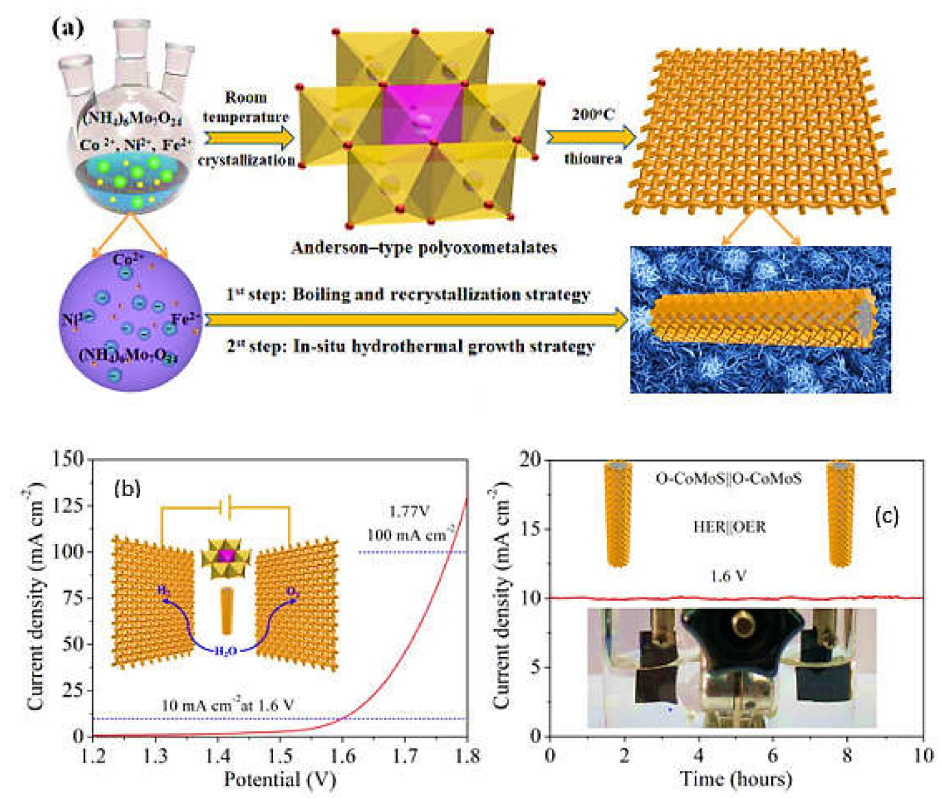

Figure 10. (a) Schematic illustration of the synthesis of as-prepared oxygenated-bimetalsulfide hetero-nanosheet arrays grown on carbon fiber cloth by use of Andersontype $\left(\mathrm{NH}_{4}\right)_{4}\left[\mathrm{M}^{\mathrm{II}} \mathrm{Mo}_{6} \mathrm{O}_{24} \mathrm{H}_{6}\right] \cdot 6 \mathrm{H}_{2} \mathrm{O}$ poly oxo metalates. (b) Overall water splitting performance and (c) time dependence of current densities under different constant potentials by the use of an O-CoMoS array as a perspective anode and cathode for overall water splitting. Copyright 2018 by American Chemical Society [78]. 
The improved OER performance the O-CoMoS nanosheet array had an enhanced overpotential of $272 \mathrm{mV}$ to deliver a current density of $10 \mathrm{~mA} \mathrm{~cm}^{-2}$ (Figure 10b). O-CoMoS exhibited an outstanding OER performance among the nanosheets prepared corresponding to the overpotentials of 286, 301 and $310 \mathrm{mV}$ at the current densities of 20,50 and $100 \mathrm{~mA} \mathrm{~cm}^{-2}$, respectively (Figure 10c). The highest electrocatalytic performance of OCoMoS architecture may be attributed to structural disorder, the active heterointerfaces exposure, the active catalytic sites and charge transport between the two conductive channels. Correspondingly, $\mathrm{MoS}_{2}-\mathrm{Ni}_{3} \mathrm{~S}_{2} \mathrm{HNRs} / \mathrm{NF}$ has been synthesized successfully via a simple hydrothermal method in which anisotropic molybdate intermediates are used to direct the development of hierarchical $\mathrm{MoS}_{2}-\mathrm{Ni}_{3} \mathrm{~S}_{2}$ hetero structures (Figure 11a).
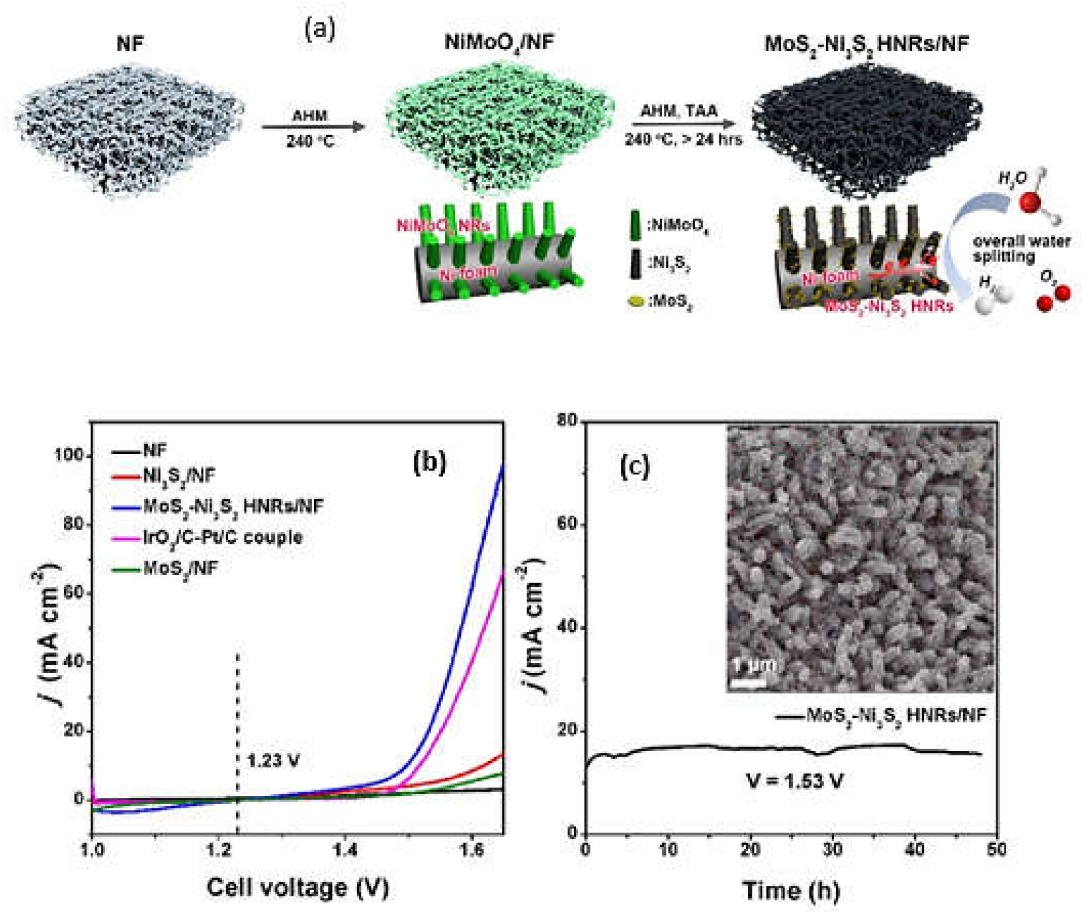

Figure 11. (a) Schematic representation of the fabrication of hetero-structured $\mathrm{MoS}_{2}-\mathrm{Ni}_{3} \mathrm{~S}_{2} \mathrm{HNRs} / \mathrm{NF}$ composites. (b) Polarization curves and (c) long-term durability tests at $1.53 \mathrm{~V}$ of $\mathrm{MoS}_{2}-\mathrm{Ni}_{3} \mathrm{~S}_{2}$ $\mathrm{HNRs} / \mathrm{NF}$ for overall water splitting in a $1.0 \mathrm{M} \mathrm{KOH}$ solution. Inset: the SEM image of $\mathrm{MoS}_{2}-\mathrm{Ni}_{3} \mathrm{~S}_{2}$ HNRs/NF after water electrolysis for 48 h. Copyright 2017 by American Chemical Society [79].

The prepared $\mathrm{MoS}_{2}-\mathrm{Ni}_{3} \mathrm{~S}_{2}$ electrocatalysts performed better in terms of OER and HER, as demonstrated by the low overpotential values of 98 and $249 \mathrm{mV}$, respectively. The $\mathrm{MoS}_{2}-\mathrm{Ni}_{3} \mathrm{~S}_{2} \mathrm{HNRs} / \mathrm{NF}$ can also be used as a bifunctional electrocatalyst for overall water splitting in a two-electrode system (Figure 11a,b). Interestingly, it provides a current density of $10 \mathrm{~mA} \mathrm{~cm}{ }^{-2}$ in $1.0 \mathrm{M} \mathrm{KOH}$ at a cell voltage of $1.50 \mathrm{~V}$, i.e., an amalgamated overpotential of $\sim 270 \mathrm{mV}$. Furthermore, when the applied voltage was adjusted to $1.53 \mathrm{~V}$, the electrolyzer provided a smooth line with a consistent current density of $\sim 17 \mathrm{~mA} \mathrm{~cm}^{-2}$ for $48 \mathrm{~h}$ (Figure 11c). It also persisted after the overall water splitting for $48 \mathrm{~h}$, showing the acceptable enduring durability of $\mathrm{MoS}_{2}-\mathrm{Ni}_{3} \mathrm{~S}_{2}$ HNRs under the strong alkaline electrolyte [79]. A few striking findings on OER catalytic activity under acidic conditions were made. The authors analyzed the $\operatorname{IrNi}(\mathrm{Ox})$ catalyst forms in the literature and identified that IrNi HT had the second-highest mass activity [80]. Shan et al., inferred a while back that the co-doped RuIr alloy considerably improved OER activity and stability under acidic conditions due to optimal oxygen-intermediate binding behavior and a lower reduced metal dissolution compared to the RuIr alloy [81]. In another study, You et al. [82] developed 3D-hierarchically porous urchin-like $\mathrm{Ni}_{2} \mathrm{P}$ microsphere superstructures anchored on nickel foam as bifunctional electrocatalysts for overall water splitting. The $\mathrm{Ni}_{2} \mathrm{P} / \mathrm{Ni} / \mathrm{NF}$ 
catalysts were prepared by a phosphidation process. The optimal $\mathrm{Ni}_{2} \mathrm{P} / \mathrm{Ni} / \mathrm{NF}$ demonstrated exceptional catalytic performance and stability for OER in alkaline electrolytes. When used as an OER electrocatalyst, $\mathrm{Ni}_{2} \mathrm{P} / \mathrm{Ni} / \mathrm{NF}$ was largely oxidized to nickel oxides/hydroxides/oxyhydroxides on the catalyst surface and showed outstanding OER activity with low overpotentials of 200 and $268 \mathrm{mV}$ reaching 10 and $100 \mathrm{~mA} \mathrm{~cm}{ }^{-2}$, respectively. Evans et al. [83] devised a new electrochemical technique for synthesizing stoichiometric, phase pure $\mathrm{CoSb}_{2} \mathrm{O}_{6}$ and $\mathrm{MnSb}_{2} \mathrm{O}_{6}$ electrodes to examine their capability to oxidize water in acidic media. When the same geometric area was employed, the electrode $\mathrm{CoSb}_{2} \mathrm{O}_{6}$ performed better; however, the performance of $\mathrm{MnSb}_{2} \mathrm{O}_{6}$ was superior when the electrochemically active surface was considered. Furthermore, both demonstrated consistent V-t performance during the OER at $10 \mathrm{~mA} / \mathrm{cm}^{2}$ after a considerable time of $24 \mathrm{~h}$ of V-t measurement. Du et al. [84] successfully prepared a polyhedron transition metal-organic framework carbon nanomaterial (Co/P/MOFs-CNTs-700) co-doped with phosphorus and carbon sources that can be used as an efficient and cheap bi-functional electrochemical catalyst. The Co/P/MOFs-CNT-s-700 exhibited the lowest overpotential of $420 \mathrm{mV}$, which achieved the current density of $10 \mathrm{~mA} \mathrm{~cm}^{-2}$ for OER, and the half potential was $0.8 \mathrm{~V}$ for ORR in $0.1 \mathrm{M} \mathrm{NaOH}$, which is extremely similar to commercial electrochemical catalysts. It might be used as a potential electrochemical bifunctional electrocatalyst in the energy storage industry, as well as providing a promising insight into electrochemical bifunctional electrocatalyst design.

\section{Energy Conversion for OER}

One of the most important concerns nowadays is energy. As conventional fossil fuels become depleted, so many socio-ecological issues have arisen. A practical solution to this challenge is the development of green and renewable energy. Previously, sophisticated electrochemical energy conversion devices, like as fuel cells [85] and water splitting [86] were extensively researched in order to produce a cost-effective, supportable, consistent, and environmentally friendly substitute to traditional energy systems. Enhancing the performance of electrochemical energy conversion systems, including ORR [87], OER [88], HER, [89] and other technologies, has taken a lot of research and engineering work. Many developed electrode materials could catalyze two or more reactions simultaneously; however, most work focuses on improving the electrocatalytic activity of a single reaction, while ignoring the synthesis of a multifunctional electrocatalyst with high activity and good longevity [90]. Herein, we discussed some of the electrocatalysts for energy conversion systems that involve OER. In alkaline conditions, $\mathrm{Ni}$ and its alloys are perhaps the most effective catalysts for the OER [91,92], whereas Ir and Ru are the most efficient catalysts in acidic media $[93,94]$.

Bizzotto et al., presented a novel, reliable and scalable approach for the synthesis and evaluation of extremely tiny and monodisperse Ir NPs with outstanding OER performance as catalysts. This catalyst is a potential option for the development of supported catalysts with an exceptionally high electrochemically active surface area due to the small Ir NPs size and the stability of the colloidal suspension [95]. ORR and OER are the two critical processes involved in metal-air batteries. Particularly, in $\mathrm{Zn}$-air batteries, these processes can create a significant impact on the total efficiency of the charge and discharge cycle. Theelectrocatalyst NC-Co SA, comprising Co single atoms anchored in porous N-doped carbon flakes, has been synthesized by a carbonization acidification method. Co-MOF was employed as a precursor and the resulting material is very sustainable.

As depicted in Figure 12a, although NC-Co SA's onset potential $\left(\mathrm{E}_{\text {onset }}=1.00 \mathrm{~V}\right.$, $\mathrm{E}_{1 / 2}=0.87 \mathrm{~V}$, vs. RHE) and half-wave potential are similar to those of NC-Co $\left(\mathrm{E}_{\text {onset }}=1.02 \mathrm{~V}\right.$, $\mathrm{E}_{1 / 2}=0.86 \mathrm{~V}$, vs. RHE), its saturation current at $0.60 \mathrm{~V}$ (vs. RHE) may reach $10.38 \mathrm{~mA} \mathrm{~cm}^{-2}$, which is significantly higher than that of NC-Co $\left(6.93 \mathrm{~mA} \mathrm{~cm}^{-2}\right)$ and the precious Pt/C catalyst $\left(8.52 \mathrm{~mA} \mathrm{~cm}^{-2}\right)$. Under three diverse voltages, the $\mathrm{K}-\mathrm{L}$ plots reveal a better linear relationship between $\mathrm{i}^{-1}$ and $\omega^{-0.5}$ (Figure 12b). In terms of the OER catalytic activities displayed in Figure 12c, when the current density approaches $10 \mathrm{~mA} \mathrm{~cm}{ }^{-2}$, NC-Co SA 
exhibits a lower overpotential $(360 \mathrm{mV})$ than thePt/C catalyst $(401 \mathrm{mV})$, demonstrating its potential OER activities. The battery using NC-Co SA as the cathode showed no voltage change (Figure 12d) after 570 charge/discharge cycles (equal to $180 \mathrm{~h}$ ), which was more stable than the battery with $\mathrm{Pt} / \mathrm{C}$ after 325 cycles (equal to $108 \mathrm{~h}$ ), demonstrating the former's outstanding cycling stability.
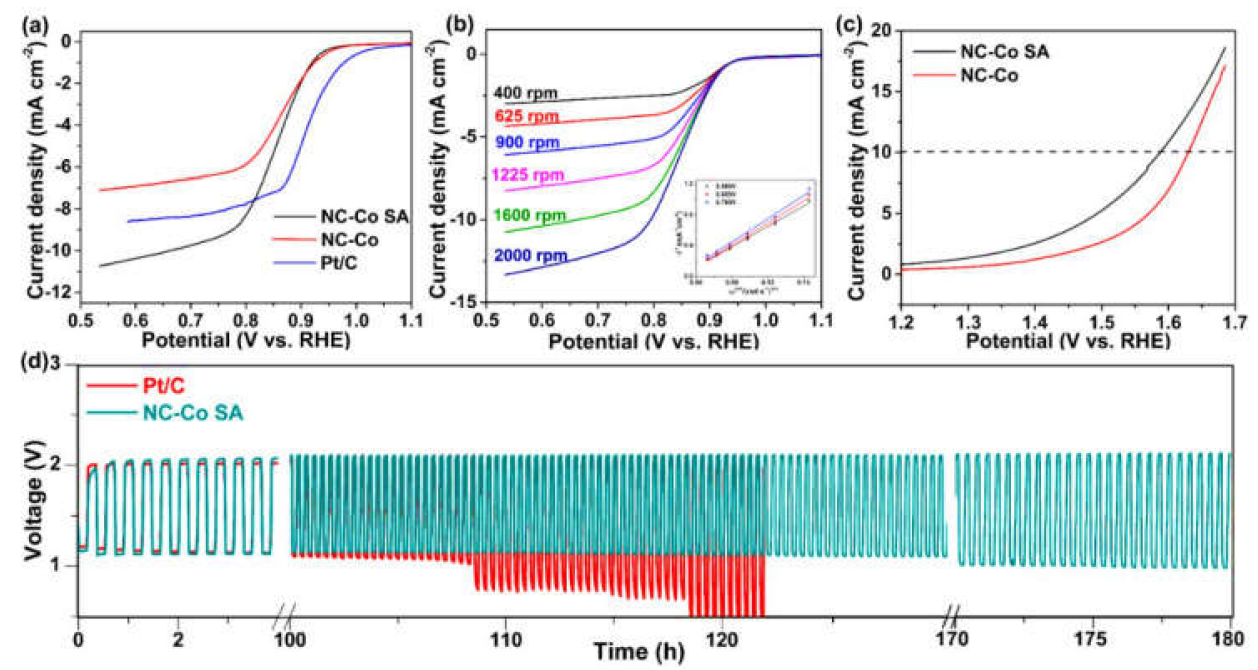

Figure 12. (a) Oxygen reduction polarization curves at the rotation speed of $1600 \mathrm{rpm}$. (b) Oxygen reduction polarization curves of NC-Co SA at different rotation speeds and Koutecky-Levich plots. (c) Oxygen evolution curves. (d) Stability test of aqueous rechargeable Zn-air batteries using NC-Co SA and Pt/C as the air cathodes. Copyright 2018 by American Chemical Society [96].

The single-atom catalysts have plenty of potential for non-noble metal-based electrocatalysts for flexible energy conversion and storage devices [96]. $\mathrm{LaNiO}_{3}$ and $\mathrm{LaNi}_{0.85} \mathrm{Mg}_{0.15} \mathrm{O}_{3}$ nanofibers were synthesized via an electrospinning method. The prepared LNMO NFs had more OER and ORR activity than $\mathrm{LaNiO}_{3}$, as well as a higher positive half-wave potential $(0.63 \mathrm{~V})$ and a lower overpotential of $0.45 \mathrm{~V}$ at a current density of $10 \mathrm{~mA} \mathrm{~cm}^{-2}$. Because the LNMO has a strong oxygen-binding surface that enhances OER activity, it could be employed as a promising bifunctional catalyst for zinc-air battery applications [97]. Exploration of non-noble metals and high-activity electrocatalysts via simple and controlled techniques continues to be a significant problem for zinc-air batteries. Cheng et al., adopted a melt polymerization strategy to synthesize iron polyphthalocyanine metallic-organic frameworks over the carbon black matrix. Through non-covalent $\pi-\pi$ interactions, FePPc molecules may be anchored on the carbon black matrix, facilitating the electron transfer process and system stability. Because of the adequate free electrons and $\mathrm{MN}_{4}$ catalytic sites in the macroscale structure, the as-synthesized FePPC@CB displays enhanced OER electrocatalytic activity. Furthermore, it also performs well in liquid and flexible all-solid-state batteries [98].

In recent decades, fuel cells have made tremendous progress in energy applications [99]. For fuel cells, it is essential to have an oxygen electrocatalyst that is both efficient and stable. Metal nitride nanosheets were prepared by Tian et al. [100] using a simple hydrothermal method. The $\mathrm{Ti}_{0.8} \mathrm{Co}_{0.2} \mathrm{~N}$ nanosheets exhibited substantial oxygen reduction activities in both acidic $\mathrm{H}_{2}$-air and alkaline $\mathrm{Zn}$-air fuel cells. Hence, the nanosheets may be employed as a potential application in the real alkaline metal-air fuel cells. Interestingly, Kuang et al. [101] developed copper, cobalt-based oxide/iron hydroxide hybrid nanowire arrays $\left(\mathrm{CuCoO}_{x} / \mathrm{FeOOH}\right)$ through a three-step growth/annealing/conversion process (Figure 13). 


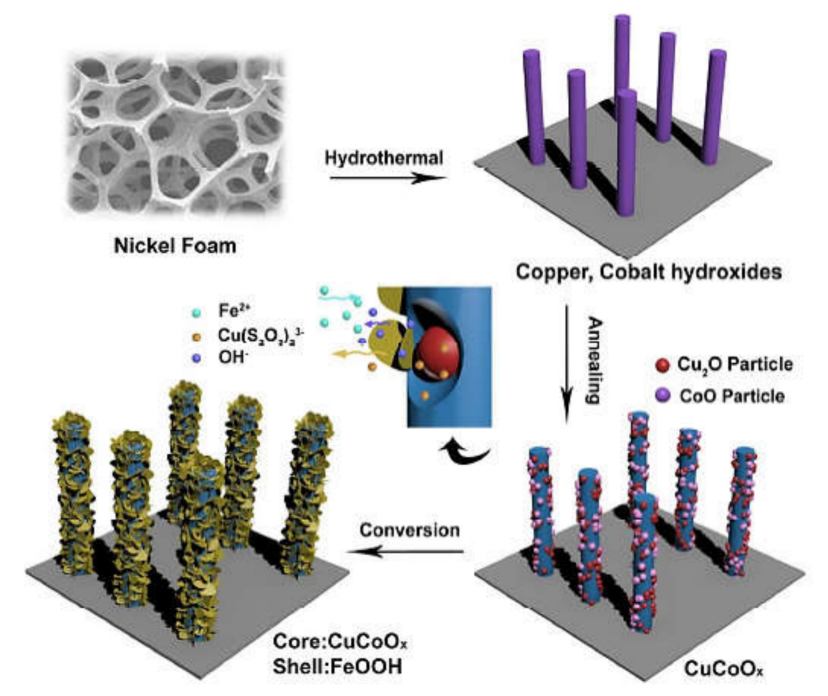

Figure 13. Schematic illustration showing the fabrication of the $\mathrm{CuCoO}_{\mathrm{x}} / \mathrm{FeOOH}$ hybrid nanowire electrocatalysts, including the growth, annealing and conversion synthesis process. Copyright 2017 by American Chemical Society [101].

A rechargeable $\mathrm{Zn}$-air battery with a moderate charge/discharge overpotential $(0.75 \mathrm{~V}$ at $10 \mathrm{~mA} \mathrm{~cm}^{-2}$ ) and long-term cycling stability (150 cycles) was constructed using the $\mathrm{CuCoO}_{\mathrm{x}} / \mathrm{FeOOH}$ electrocatalyst as the oxygen electrode, indicating novel bifunctional electrocatalysts for energy conversion and storage applications. Hierarchical porous doubleshelled $(\mathrm{MgCo})_{3} \mathrm{O}_{4}$ electrocatalysts with controllable $\mathrm{Mg}$ substitution have been synthesized via an insitu method. Mg substitution, in particular, improves electrical conductivity and affects electrocatalysis by inducing lattice buffer zones. The findings of this study provide an encouraging insight into the rational design of efficient oxygen electrocatalysis for real-world energy conversion systems [102].

\section{Conclusions and Future Perspectives}

In this article, we focused on the development of new types of efficient electrocatalysts for OER applications, owing to the easy formation, surface engineering, cost-effective and regulating energy conversion and energy storage system. In summary, we highlighted the most dynamic natured metal oxides embedded onto functionalized carbon and conductivepolymer-based materials, which can help realize their catalytic activity and long-term stability towards OER. More precisely, we systematically analyzed OER electrocatalysts with massive electrocatalytic activity, desirable mass activity, rapid energy conversion and storage technologies that are still challenging. With this perspective, the focused nanocomposite's structure activity relationship will get a new approach and better understanding for the development of sustainable energy resources. Consequently, we discussed advanced electrocatalysts that could provide new promising energy sources for OER, as well as their general mechanisms and outcomes in terms of catalytic performance, low overpotential, electrode stability and Tafel slope measurment. The simple and costeffective routes for the fabrication of functionalized nanocomposite materials should be developed and the detailed mechanistic aspects are highlighted herein. More emphasis on the various nanostructured electrocatalysts have significantly proved their promise in fuel cell catalysts. The applications of highly conductive natured $\mathrm{CNF}, \mathrm{Co}_{3} \mathrm{O}_{4}, 3 \mathrm{D}$ graphene and $\mathrm{NiCO}_{2} \mathrm{O}_{4}$ in OER have led to improvements in their catalytic activity. In particularly, the construction of highly monodispersed and structurally ordered electrocatalysts will have major research impacts in the future.

Supplementary Materials: The following are available online at https: / www.mdpi.com/article / 10.3390/ma14164420/s1, Table S1: Summary of OER electrocatalytic activities of the summarized different kinds of advanced electrocatalysts. 
Author Contributions: Conceptualization, T.-W.C., R.R. and S.-M.C.; Resources, P.K., G.A., R.R., T.W.C., S.-M.C. and V.M.; Supervision, R.R., P.K., G.A. and S.-M.C.; Writing—original draft preparation, R.R., T.-W.C., S.-M.C., P.K., G.A. and V.M.; Writing-review and editing, R.R., T.-W.C., S.-M.C., P.K., G.A. and V.M., Scheme Design, R.R. and V.M. All authors have read and agreed to the published version of the manuscript.

Funding: S.-M.C. received funding from Ministry of Science and Technology (MOST 110-2113-M027-003) Taiwan (ROC). R.R received financial support from the Science and Engineering Research Board (SERB), Government of India, New Delhi, File No. EEQ/2016/000427.

Institutional Review Board Statement: Not applicable.

Informed Consent Statement: Not applicable.

Data Availability Statement: Data are contained within the article or the Supplementary Materials.

Conflicts of Interest: The authors declare no conflict of interest.

\section{References}

1. Baek, M.; Kim, G.W.; Park, T.; Yong, K. NiMoFe and NiMoFeP as complementary electrocatalysts for efficient over all water splitting and their applicationin PV-electrolysis with STH1 2.3\%. Small 2019, 15, 1905501. [CrossRef]

2. Yong, J.; Wang, X.; Li, B.; Ma, L.; Shi, L.; Xiong, Y.; Xu, H. Noveliron/cobalt-containing polypyrrole hydrogel-derived tri-functional electrocatalyst for self-powered over all water splitting. Adv. Funct. Mater. 2017, 27, 1606497. [CrossRef]

3. Qin, Q.; Jang, H.; Li, P.; Yuan, B.; Li, X.; Cho, J. Atannic acid-derived N,P-co-doped carbon-supported iron-based nanocomposite as an advanced tri-functional electrocatalyst for the overall water splitting cells and zinc-air batteries. Adv. Energy Mater. 2018, 9, 1803312. [CrossRef]

4. Zhang, W.; Lai, W.; Cao, R. Energy related small molecules activation reactions: Oxygen reduction reaction and hydrogen and oxygen evolution reaction catalyzed by phorphyrin and corrole-based systems. Chem. Rev. 2017, 117, 3717-3797. [CrossRef] [PubMed]

5. Ma, T.; Jin, S.; Kong, X.; Lv, M.; Wang, H.; Luo, X.; Tan, H.; Li, Z.; Zhang, Y.; Chang, X.; et al. Plasma engraved $\mathrm{Bi}_{2} \mathrm{MoO}_{6}$ nanosheet arrays towards high performance supercapacitor and oxygen evolution reaction. Appl. Surf. Sci. 2021, 548, 149244. [CrossRef]

6. Rezaei, B.; Reza, A.; Jahromi, T.; Ensafi, A.A. $\mathrm{Co}(\mathrm{OH})_{2}$ nanoparticles deposited on reduced graphene oxide nano flake as a suitable electrode material for supercapacitor and oxygen evolution reaction in alkaline media. Int. J. Hydrogen Energy 2017, 42, 16538-16546. [CrossRef]

7. Wang, X.; Li, L.; Xu, L.; Wang, Z.; Wu, Z.; Liu, Z.; Yangs, P. An efficient and stable MnCo@NiS catalyst for oxygen evolution reaction constructed by a step-by-step electro deposition way. J. Power Sources 2021, 489, 229525. [CrossRef]

8. Wang, T.; Fu, X.Z.; Wang, S. Etching oxide over layers of NiFe phosphide to facilitate surface reconstruction for oxygen evolution reaction. Green Energy Environ. 2021. [CrossRef]

9. Vij, V.; Sultan, S.; Harsandi, A.M.; Meena, A.; Tiwari, J.N.; Lee, W.G.; Yoon, T.; Kim, K.S. Nickel based electrocatalysts for energy related applications; oxygen reduction, oxygen evolution and hydrogen evolution reactions. ACS Catal. 2017, 7, 7196-7225. [CrossRef]

10. Li, Y.; Jiang, L.; Liu, F.; Li, J.; Liu, Y. Novel phosphorous-doped $\mathrm{PbO}_{2}-\mathrm{MnO}_{2}$ bi-continuous electrodes for oxygen evolution reaction. RSC Adv. 2014, 4, 24020.

11. Ko, J.S.; Johnson, J.K.; Johnson, P.I.; Xia, Z. Decoupling oxygen and chlorine evolution reaction in sea water using Iridium-based electrocatalysts. Chem. Cat. Chem. 2020. [CrossRef]

12. Zhang, Y.; Ye, F.; Li, W. Self-assembly two-dimensional $\mathrm{NiO} / \mathrm{CeO}_{2}$ hetero structure rich in oxygen vacancies as efficientbifunctional electrocatalyst for alkaline hydrogen evolution and oxygen evolution. Chem. Eur. J. 2020. [CrossRef]

13. Yang, Y.; Dang, L.; Shearer, M.J.; Sheng, H.; Li, W.; Chen, J.; Xiao, P.; Zhang, Y.; Hamers, R.J.; Jin, S. Highly active tri-metallic $\mathrm{NiFeCr}$ layered double hydroxide electrocatalysts for oxygen evolution reaction. Adv. Energy. Mater. 2018, 8, 1703189. [CrossRef]

14. Wang, L.; Gu, C.; Ge, X.; Zheng, J.; Zhu, H.; Tu, J. Decorating $\mathrm{NiCo}_{2} \mathrm{O}_{4}$ shell on a hollow Ni nano rod array core for water splitting with enhanced electrocatalytic performance. Chem. Nano Mater. 2017, 4, 124-131.

15. Li, X.; Wei, J.; Li, Q.; Zheng, S.; Xu, Y.; Du, P.; Chen, C.; Zhao, J.; Xue, H.; Xu, Q.; et al. Nitrogen-doped cobalt oxide nanostructured derived from cobalt alanine complexes for high performances oxygen evolution reactions. Adv. Funct. Mater. 2018, 28, 1800886. [CrossRef]

16. Broicher, C.; Zheng, F.; Artz, J.; Hartmann, H.; Besmehn, A.; Palkovits, S.; Palkovits, R. Facile synthesis of mesoporous nickelcobaltoxide for OER-insight in to intrinsic electrocatalytic activity. ChemCatChem 2018. [CrossRef]

17. Yao, R.Q.; Shi, H.; Wan, W.B.; Wen, Z.; Lang, X.Y.; Jiang, Q. FlexibleCo-Mo-N/Au electrodes with a hierarchical nanoporous architecture as highly efficient electrocatalyst for oxygen evolution reaction. Adv. Mater. 2020, 32, 1907214. [CrossRef] [PubMed]

18. Shi, Y.; Yu, Y.; Liang, Y.; Du, Y.; Zheng, B. In situ electrochemical conversion of an ultrathin tannin nickel ironcomplex film as an efficient oxygen evolution reaction electrocatalyst. Angew. Chem. Int. Ed. 2019, 58, 3769-3773. [CrossRef] [PubMed] 
19. Kundu, S.; Malik, B.; Pattanayak, D.K.; Ragupathy, P.; Pillai, V.K. Role of specific N-containing active sites in interconnectedgraphene quantum dots for the enhanced electrocatalytic activity connected graphene quantum dots for the enhanced electrocatalytic activity towards oxygen evolution reaction. Chem. Sel. 2017, 2, 9943-9946.

20. Surendran, S.; Shanmugapriya, S.; Lee, Y.S.; Sim, U.; Kalaiselvan, R. Carbon-enriched cobalt phosphide with as sorted nanostructure as a multi-functional electrode for energy conversion and storage devices. Chem. Sel. 2018, 3, 12303-12313.

21. Qian, W.; Cao, M.; Xie, F.; Dong, C. Thermo electrochemical cells based on carbon nanotube electrodes by electrophoretic deposition. Nano-Micro Lett. 2016, 8, 240-246. [CrossRef]

22. Hu, R.; Cola, B.A.; Haram, N.; Barisci, J.N.; Lee, S.; Stoughton, S.; Wallace, G.; Too, C.; Thomas, M.; Gestos, A.; et al. Harvesting waste thermal energy using a carbon-nanotube based thermo electrochemical cell. Nano Lett. 2010, 10, 838-846. [CrossRef] [PubMed]

23. Li, T.; Lv, Y.; Su, J.; Wang, Y.; Yang, Q.; Zhang, Y.; Zhou, J.; Xu, L.; Sun, D.; Tang, Y. AnchoringCoFe $\mathrm{O}_{4}$ nanoparticles on N-doped carbon nanofiber for high performance oxygen evolution reaction. Adv. Sci. 2017, 4, 1700226. [CrossRef] [PubMed]

24. Peng, X.; Chen, X.; Liu, T.; Lu, C.; Sun, M.; Ding, F.; Wang, Y.; Zou, P.; Wang, X.; Zhao, X.; et al. Rose-like nanocomposite of Fe-Ni phosphides/Iron oxides as efficient catalyst for oxygen evolution reaction. Chem. Asian J. 2019. [CrossRef]

25. Yan, K.; Lu, Y. Direct growth of $\mathrm{MoS}_{2}$ microspheres on $\mathrm{Ni}$ foam as a hybrid nanocomposite efficient for oxygen evolution reaction. Small 2016, 12, 2975-2981. [CrossRef]

26. Sharma, V.; Biswas, S.; Sundaram, B.; Haldar, P.; Dubey, B.; Chandra, A. Electrode materials with highest surface area and specific capacitance cannot be the only the deciding factor for applicability in energy storage devices; Inference of combined life cycle assessment and electrochemical studies. ACS Sustain. Chem. Eng. 2019, 7, 5385-5392. [CrossRef]

27. Lv, S.; Chen, J.; Chen, X.; Chen, J.; Li, Y. Simple 2D/0D CoP integration in a metal-organic frame work derived bifunctional electrocatalyst for efficient over all water splitting. ChemSusChem 2020. [CrossRef] [PubMed]

28. Lubke, M.; Sumboja, A.; McCafferty, L.; Armer, C.F.; Handoko, A.D.; Du, Y.; McColl, K.; Cora, F.; Brett, D.; Liu, Z.; et al. Transitional-metal-doped $\alpha-\mathrm{MnO}_{2}$ nanorods as bi-functional catalyst for efficient oxygen reduction and evolution reaction. Chem. Sel. 2018, 3, 2613-2622.

29. Zhang, J.; Zhang, M.; Zeng, Y.; Chen, J.; Qui, L.; Zhou, H.; Sun, C.; Yu, Y.; Zhu, C.; Zhu, Z. Single Fe atom on hierarchically porous $\mathrm{S}, \mathrm{N}$-co-doped nano carbon derived from porphyraenable boosted oxygen catalyst for rechargeable Zn-air batteries. Small 2019, 15, 1900307. [CrossRef] [PubMed]

30. Wahab, M.A.; Joseph, J.; Atanda, L.; Sultana, U.K.; Beltramini, J.N.; Ostrikov, K.; Will, G.; Mullane, P.O.; Abdala, A. Nano confined synthesis of nitrogen-rich metal-free meso porous carbon nitride electro catalyst for the oxygen evolution reaction. ACS Appl. Energy Mater. 2020. [CrossRef]

31. Zhang, W.; Zhao, X.; Zhao, Y.; Zhang, J.; Li, X.; Fang, L.; Li, L. Mo-doped Zn, Cozeolite-imidazolate framework-derived Co $9 S_{8}$ quantum dot sandMoS 2 embedded in three-dimensional nitrogen doped carbon nanoflake arrays as an efficient tri-functional electrocatalysts for ORR, OER and HER. ACS Appl. Mater. Interfaces 2020. [CrossRef]

32. Qiao, X.; Liao, S.; Zheng, R.; Deng, Y.; Song, H.; Du, L. Cobalt and nitrogenco-doped graphene with inserted carbon nanospheres as an efficient bi-functional electrocatalyst for oxygen reduction and evolution. ACS Sustain. Chem. Eng. 2016, 4, 4131-4136. [CrossRef]

33. Baehr, A.; Moon, G.H.; Tuysuz, H. Nitrogen-doped meso structured carbon supported metallic cobalt nanoparticles for oxygen evolution reaction. ACS Appl. Energy Mater. 2019. [CrossRef]

34. Song, J.; Wei, C.; Huang, Z.F.; Liu, C.; Zeng, L.; Wang, X. A review on fundamentals for designing oxygen evolution electrocatalysts. Chem. Soc. Rev. 2020, 49, 2196-2214. [CrossRef] [PubMed]

35. Kundu, A.; Ryplida, B.; Park, S.Y. Carbon Dots Integrated $\mathrm{NiCo}_{2} \mathrm{O}_{4}$ Hierarchical Nanoneedle Arrays Supported on Ni Foam as Efficient and Stable Electrode for Hydrogen and Oxygen Evolution Reactions. Electroanalysis 2020, 32, 2090-2100. [CrossRef]

36. Sun, Z.; Wang, X.; Zhao, H.; Koh, S.W.; Ge, J.; Zhao, Y. Rambutan-like hollow carbon spheres decorated with vacancy-rich nickel oxide for energy conversion and storage. Carbon Energ. 2020, 2, 122-130. [CrossRef]

37. Wang, J.; Zhong, H.X.; Qin, Y.L.; Zhang, X.B. An Efficient Three-Dimensional Oxygen Evolution Electrode. Angew. Chem. Int. Ed. 2013, 52, 5248-5253. [CrossRef]

38. Zhang, Y.; Ouyang, B.; Xu, J.; Jia, G.; Chen, S.; Rawat, R.S. Rapid Synthesis of Cobalt Nitride Nanowires: Highly Efficient and Low-Cost Catalysts for Oxygen Evolution. Angew. Chem. Int. Ed. 2016, 55, 8670-8674. [CrossRef] [PubMed]

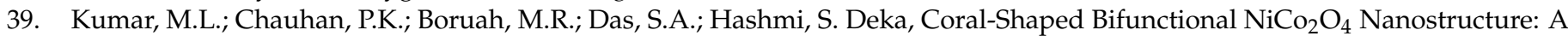
Material for Highly Efficient Electrochemical Charge Storage and Electrocatalytic Oxygen Evolution Reaction. ACS Appl. Energy Mater. 2020, 3, 6793-6804. [CrossRef]

40. Guo, D.; Kang, H.; Hao, Z.; Yang, Y.; Wei, P.; Zhang, Q. Mesoporous cobalt-iron based materials as highly efficient electro catalysts for oxygen evolution reaction. J. Electroanal. Chem. 2020, 873, 114443. [CrossRef]

41. Li, X.; Qian, X.; Xu, Y.; Wu, H.; Dan, Y.; Chen, L. Fe-Co-P/C with strong coupling interaction for enhanced sodium ion batteries and oxygen evolution reactions. Electrochim. Acta. 2019, 321, 134646. [CrossRef]

42. Kalimuthu, P.; Belaidi, A.A.; Schwarz, G.; Bernhardt, P.V. Chitosan-Promoted Direct Electrochemistry of Human Sulfite Oxidase. J. Phys. Chem. B 2017, 121, 9149-9159. [CrossRef]

43. Kalimuthu, P.; Suresh, D.; John, S.A. Uric acid determination in the presence of ascorbic acid using self-assembled submonolayer of dimer captothiadiazole-modified gold electrodes. Anal. Biochem. 2006, 357, 188-193. [CrossRef] [PubMed] 
44. Kalimuthu, P.; Havemeyer, A.; Clement, B.; Kubitza, C.; Scheidig, A.J.; Bernhardt, P.V. Human mitochondrialamidoxime reducing component (mARC): An electrochemical method for identifying new substrates and inhibitors. Electrochem. Commun. 2017, 84, 90-93. [CrossRef]

45. Liu, P.P.; Zhu, H.L.; Zheng, Y.Q. Hybrid MnO/C nanorod arrays derived from a MOF precursor with enhanced oxygen evolution activity. J. Mater. Sci. 2018, 53, 11574-11583. [CrossRef]

46. Morales, D.V.; Astudillo, C.N.; Lattach, Y.; Urbano, B.F.; Pereira, E.; Rivas, B.L. Nickel oxide-polypyrrole nanocomposite electrode materials for electro catalytic water oxidation. Catal. Sci. Technol. 2018, 8, 4030-4043. [CrossRef]

47. Doyle, R.L.; Godwin, I.J.; Brandon, M.P.; Lyons, M.E.G. Redox and electrochemical water splitting catalytic properties of hydrated metaloxide modified electrodes. Phys. Chem. Chem. Phys. 2013, 15, 13737-13783. [CrossRef]

48. Kuznetsov, D.A.; Konev, D.V.; Komarova, N.Y.S.; Ionov, A.M.; Mozhchil, R.N.; Fedyanin, I.V. Ni-based heterogeneous catalyst from a designed molecular precursor for the efficient electrochemical water oxidation. Chem. Commun. 2016, 52, 9255-9258. [CrossRef] [PubMed]

49. Kang, B.; Shi, H.; Wu, S.; Zhao, W.; Ai, H.; Lee, J.Y. Revealing the importance of nitrogen doping site in enhancing the oxygen reduction reactionon $\beta$-graphyne. Carbon 2017, 123, 415-420. [CrossRef]

50. Zhang, K.; Xia, X.; Deng, S.; Zhong, Y.; Xie, D.; Pan, G. Nitrogen-doped sponge Ni fibers as highly efficient electrocatalysts for oxygen evolution reaction. Nano-Micro Lett. 2019, 11, 21. [CrossRef]

51. Li, W.; Shen, Q.; Men, D.; Sun, Y.; Cao, W.; Lee, J.Y. Porous CoSe ${ }_{2} @$ N-doped carbon nanowires: An ultra-high stable and large-current-density oxygen evolution electro catalyst. Chem. Commun. 2021, 57, 1774-1777. [CrossRef]

52. Liu, X.; Zhang, M.; Yang, T.; Wang, L.; Zhu, H.; Wang, S. Carbon nano fibers as nanoreactors in the construction of Pt Co alloy carbon core-shell structures for highly efficient and stable water splitting. Mater. Des. 2016, 109, 162-170. [CrossRef]

53. Sharma, R.; Khan, S.; Goyal, V.; Sharma, V.; Sharma, K.S. Investigation on effect of boron and nitrogen substitution on electronic structure of graphene. Flat Chem. 2017, 1, 20-33. [CrossRef]

54. Kim, Y.A.; Fujisawa, K.; Muramatsu, H.; Hayashi, T.; Endo, M.; Fujimori, T. Raman Spectroscopy of Boron-Doped Single-Layer Graphene. ACS Nano 2012, 6, 6293-6300. [CrossRef] [PubMed]

55. Joshi, P.; Huang, H.H.; Yadav, R.; Hara, M.; Yoshimura, M. Boron-doped graphene as electrocatalytic support for iridium oxide for oxygen evolution reaction. Catal. Sci. Technol. 2020, 10, 6599-6610. [CrossRef]

56. Li, B.; Xing, R.; Mohite, S.V.; Latthe, S.S.; Fujishima, A.; Liu, S. $\mathrm{CoS}_{2}$ nanodots anchored into heteroatom-doped carbon layer via a biomimetic strategy: Boosting the oxygen evolution and supercapacitor performance. J. Power Sources 2019, $436,226862$. [CrossRef]

57. Sun, T.; Wang, J.; Qiu, C.; Ling, X.; Tian, B.; Chen, W.B. NCo doped and Defect-Rich Nano carbon Material as a Metal-Free Bifunctional Electrocatalyst for Oxygen Reduction and Evolution Reactions. Adv. Sci. 2018, 5, 1800036. [CrossRef]

58. Yang, L.J.; Jiang, S.J.; Zhao, Y.; Zhu, L.; Chen, S.; Wang, X.Z. Boron-doped carbon nanotubes as metal-free electrocatalysts for the oxygen reduction reaction. Angew. Chem. Int. Ed. 2011, 50, 7132-7135. [CrossRef] [PubMed]

59. Kalimuthu, P.; Hsiao, J.C.; Nair, R.P.; Kappler, U.; Bernhardt, P.V. Bioelectrocatalysis of Sulfite Dehydrogenase from Si nor hizobiummeliloti with Its Physiological Cytochrome Electron Partner. Chem. Electro Chem. 2017, 4, 3163-3170.

60. Liu, H.; Liu, X.; Wang, S.; Liu, H.K.; Li, L. Transition metal based battery-type electrodes in hybrid supercapacitors: A review. Energy Storage Mater. 2020, 28, 122-145. [CrossRef]

61. Delbari, S.A.; Ghadimi, L.S.; Hadi, R.; Farhoudian, S.; Nedaei, M.; Babapoor, A.; Namini, A.S.; Le, Q.V.; Shokouhimehr, M.; Asl, M.S.; et al. Transition metal oxide-based electrode materials for flexible supercapacitors: A review. J. Alloys Compd. 2021, 857, 158281. [CrossRef]

62. Qin, J.F.; Yang, M.; Hou, S.; Dong, B.; Chen, T.S.; Ma, X. Copper and cobalt co-doped $\mathrm{Ni}_{3} \mathrm{~S}_{2}$ grown on nickel foam for highly efficient oxygen evolution reaction. Appl. Surf. Sci. 2020, 502, 144172. [CrossRef]

63. Zhang, D.; Peng, L.; Yang, Z.; Yang, Y.; Li, H. Gold-Supported Nanostructured NiFeCoPr Hydroxide as a High-Performance Supercapacitor Electrode and Electrocatalyst toward the Oxygen Evolution Reaction. Inorg. Chem. 2019, 58, 15841-15852. [CrossRef]

64. Qian, L.; Lu, Z.; Xu, T.; Wu, X.; Tian, Y.; Li, Y. Trinary Layered Double Hydroxides as High-Performance Bifunctional Materials for Oxygen Electrocatalysis. Adv. Energy Mater. 2015, 5, 1500245. [CrossRef]

65. Man, H.W.; Tsang, C.S.; Li, M.M.J.; Mo, J.; Huang, B.; Lee, L.Y.S. Tailored transition metal-doped nickel phosphide nanoparticles for the electrochemical oxygen evolution reaction (OER). Chem. Commun. 2018, 54, 8630-8633. [CrossRef]

66. Tolentino, M.O.; Samperio, J.V.; Velazquez, M.T.; Moreno, J.F.; Rojas, L.L.; Huerta, R.D.G. Bifunctional electrocatalysts for oxygen reduction/evolution reactions derived from NiCoFe LDH materials. J. Appl. Electrochem. 2018, 48, 947-957. [CrossRef]

67. Feng, J.X.; Ye, S.H.; Xu, H.; Tong, Y.X.; Li, G.R. Design and Synthesis of FeOOH/CeO 2 Heterolayered Nanotube Electrocatalysts for the Oxygen Evolution Reaction. Adv. Mater. 2016, 28, 4698-4703. [CrossRef] [PubMed]

68. Zhu, Y.; Zhou, W.; Sunarso, J.; Zhong, Y.; Shao, Z. Phosphorus Doped Perovskite Oxide as Highly Efficient Water Oxidation Electrocatalyst in Alkaline Solution. Adv. Funct. Mater. 2016, 26, 5862-5872. [CrossRef]

69. Yang, X.; Li, H.; Lu, A.Y.; Min, S.; Idriss, Z.; Hedhili, M.N.; Huang, K.W.; Idriss, H.; Li, L.J. Highly acid- durable carbon coated $\mathrm{Co}_{3} \mathrm{O}_{4}$ nanoarrays as oxygen evolution electrocatalysts. Nano Energy 2016, 25, 42-50. [CrossRef]

70. Ma, C.; $\mathrm{Xu}, \mathrm{N}$.; Qiao, J.; Jian, S.; Zhang, J. Facile synthesis of $\mathrm{NiCo}_{2} \mathrm{O}_{4}$ nanosphere-carbon nanotubes hybrid as an efficient bifunctional electrocatalyst for rechargeable Zn-air batteries. Int. J. Hydrogen Energy 2016, 41, 9211-9218. [CrossRef] 
71. Du, P.; Eisenberg, R. Catalysts made of earth-abundant elements (Co, Ni, Fe) for water splitting: Recent Progress and Future Challenges. Energy Environ. Sci. 2012, 5, 6012-6021. [CrossRef]

72. Jahan, M.; Liu, Z.; Loh, K.P. A Graphene Oxide and Copper-Centered Metal Organic Framework Composite as a Tri-Functional Catalyst for HER, OOR and OER. Adv. Funct. Mater. 2013, 23, 5363-5372. [CrossRef]

73. Kibsgaard, J.; Jaramillo, T.F. Molybdenum Phosphosulfide: An Active, Acid-Stable, Earth-Abundant Catalyst for the Hydrogen Evolution Reaction. Angew. Chem. Int. Ed. 2014, 53, 14433-14437. [CrossRef] [PubMed]

74. Long, X.; Li, J.; Xiao, S.; Yan, K.; Wang, Z.; Chen, H.; Yang, S. A strongly coupled graphene and FeNi double hydroxide hybrid as an excellent electrocatalyst for the oxygen evolution reaction. Angew. Chem. Int. Ed. 2014, 53, 7584-7588. [CrossRef] [PubMed]

75. Tahir, M.; Pan, L.; Idrees, F.; Zhang, X.; Wang, L.; Zou, J.J.; Wang, Z.L. Electrocatalytic oxygen evolution reaction for energy conversion and storage: A comprehensive review. Nano Energy 2017, 37, 136-157. [CrossRef]

76. Gautam, R.P.; Pan, H.; Chalyavi, F.; Tucker, M.J.; Barile, C.J. Nanostructured Ni-Cu electrocatalysts for the oxygen evolution reaction. Catal. Sci. Technol. 2020, 1-9. [CrossRef]

77. Han, X.; Tong, X.; Wu, G.; Yang, N.; Guo, X.Y. Carbon Fibers Supported NiSe Nanowire Arrays as Efficient and Flexible Electrocatalysts for the Oxygen Evolution Reaction. Carbon 2018, 1-19. [CrossRef]

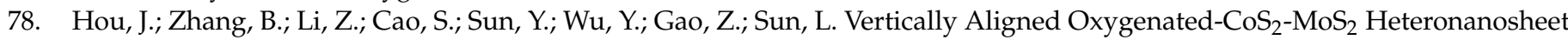
Architecture from Polyoxometalate for Efficient and Stable Overall Water Splitting. ACS Catal. 2018, 1-39. [CrossRef]

79. Yang, Y.; Zhang, K.; Lin, H.; Li, X.; Chan, H.C.; Yang, L.; Gao, Q. $\mathrm{MoS}_{2}-\mathrm{Ni}_{3} \mathrm{~S}_{2}$ Heteronanorods as Efficient and Stable Bifunctional Electrocatalysts for Overall Water Splitting. ACS Catal. 2017, 7, 2357-2366. [CrossRef]

80. Spori, C.; Briois, P.; Nong, H.N.; Reier, T.; Billard, A.; Kuhl, S.; Teschner, D.; Strasser, P. Experimental Activity Descriptors for Iridium-Based Catalysts for the Electrochemical Oxygen Evolution Reaction (OER). ACS Catal. 2019, 9, 6653-6663. [CrossRef]

81. Shan, J.; Ling, T.; Davey, K.; Zheng, Y.; Qiao, S.Z. Transition Metal-Doped RuIr Bifunctional Nanocrystals for Overall Water Splitting in Acidic Environments. Adv. Mater. 2019, 31, 1900510. [CrossRef]

82. You, B.; Jiang, N.; Sheng, M.; Bhushan, W.; Sun, Y. Hierarchically Porous Urchin-like Ni 2 P Superstructures Supported on Nickel Foam as Efficient Bifunctional Electrocatalysts for Overall Water Splitting. ACS Catal. 2016, 6, 714-721. [CrossRef]

83. Evans, T.A.; Choi, K.S. Electrochemical Synthesis and Investigation of Stiochiometric, Phase-Pure $\mathrm{CoSb}_{2} \mathrm{O}_{6}$ and $\mathrm{MnSb}_{2} \mathrm{O}_{6}$ Electrodes for the Oxygen Evolution Reaction in Acidic Media. ACS Appl. Energy Mater. 2020, 1-9. [CrossRef]

84. Du, L.; Lv, M.; Liu, D.; Song, H. An Efficient Bifunctional Electrocatalyst of Phosphorus Carbon Co-doped MOFs. Nanoscale Ress. Lett. 2020, 15, 1-11.

85. Cano, Z.P.; Banham, D.; Ye, S.; Hintennach, A.; Lu, J.; Fowler, M.; Chen, Z. Batteries and Fuel Cells for Emerging Electric Vehicle Markets. Nat. Energy 2018, 3, 279-289. [CrossRef]

86. Roger, I.; Shipman, M.A.; Symes, M.D. Earth-abundant Catalysts for Electrochemical and Photoelectrochemical Water Splitting. Nat. Rev. Chem. 2017, 1, 0003. [CrossRef]

87. Chen, Y.; Ji, S.; Zhao, S.; Chen, W.; Dong, J.; Cheong, W.-C.; Shen, R.; Wen, X.; Zheng, L.; Rykov, A.I.; et al. Enhanced Oxygen Reduction with Single-Atomic-Site Iron Catalysts for a Zinc-Air Battery and Hydrogen-Air Fuel Cell. Nat. Commun. 2018, 9, 5422. [CrossRef]

88. Wang, Q.; Ji, Y.; Lei, Y.; Wang, Y.; Wang, Y.; Li, Y.; Wang, S. Pyridinic-N-Dominated Doped Defective Graphene as a Superior Oxygen Electrocatalyst for Ultrahigh-Energy-Density Zn-Air Batteries. ACS Energy Lett. 2018, 3, 1183-1191. [CrossRef]

89. Xia, Z. Hydrogen Evolution: Guiding Principles. Nat. Energy 2016, 1, 16155. [CrossRef]

90. Tian, X.L.; Xu, Y.Y.; Zhang, W.; Wu, T.; Xia, B.Y.; Wang, X. Unsupported Platinum-Based Electrocatalysts for Oxygen Reduction Reaction. ACS Energy Lett. 2017, 2, 2035-2043. [CrossRef]

91. Yu, X.-Y.; Feng, Y.; Guan, B.; Lou, X.W.; Paik, U. Carbon Coated Porous Nickel Phosphides Nanoplates for Highly Efficient Oxygen Evolution Reaction. Energy Environ. Sci. 2016, 9, 1246-1250. [CrossRef]

92. Lu, X.; Zhao, C. Electrodeposition of Hierarchically Structured Three-Dimensional Nickel-Iron Electrodes for Efficient Oxygen Evolution at High Current Densities. Nat. Commun. 2015, 6, 6616. [CrossRef]

93. McCrory, C.C.L.; Jung, S.; Ferrer, I.M.; Chatman, S.M.; Peters, J.C.; Jaramillo, T.F. Benchmarking Hydrogen Evolving Reaction and Oxygen Evolving Reaction Electrocatalysts for Solar Water Splitting Devices. J. Am. Chem. Soc. 2015, 137, 4347-4357. [CrossRef] [PubMed]

94. Katsounaros, I.; Cherevko, S.; Zeradjanin, A.R.; Mayrhofer, K.J.J. Oxygen Electrochemistry as a Cornerstone for Sustainable Energy Conversion. Angew. Chem. Int. Ed. 2014, 53, 102-121. [CrossRef] [PubMed]

95. Bizzotto, F.; Quinson, J.; Zana, A.; Kirkensgaard, J.J.K.; Dworzak, A.; Oezaslan, M.; Arenz, M. Ir nanoparticles with ultrahigh dispersion as oxygen evolution reaction (OER) catalyst: Synthesis and activity benchmarking. Catal. Sci. Technol. 2019, 1-39. [CrossRef]

96. Zang, W.; Sumboja, A.; Ma, Y.; Zhang, H.; Wu, Y.; Wu, S.; Wu, H.; Liu, Z.; Guan, C.; Wang, J.; et al. Single Co Atoms Anchored in Porous N-doped Carbon for Efficient Cathode in Zinc-air Battery. ACS Catal. 2018, 1-30. [CrossRef]

97. Chen, T.W.; Kalimuthu, P.; Anushya, G.; Chen, S.M.; Ramachandran, R.; Vinitha, M.; Muthumala, D. High-Efficiency of BiFunctional-Based Perovskite Nanocomposite for Oxygen Evolution and Oxygen Reduction Reaction: An Overview. Materials 2021, 14, 2976. [CrossRef] [PubMed]

98. Cheng, W.; Liang, J.L.; Yin, H.B.; Wang, Y.J.; Yan, W.F.; Zhan, J.N. Bifunctional iron-phtalocyanine metal-organic framework catalyst for ORR, OER and rechargeable zinc-air battery. Rare Metals 2020, 39, 315-823. [CrossRef] 
99. Chen, T.W.; Ramachandran, R.; Chen, S.M.; Anushya, G.; Divya Rani, S.; Vinitha, M.; Elumalai, P.; Vasimalai, N. HighPerformance-Based Perovskite-Supported Nanocomposite for the Development of Green Energy Device Applications: An Overview. Nanomaterials 2021, 11, 1006. [CrossRef]

100. Tian, X.L.; Wang, L.; Chi, B.; Xu, Y.; Zaman, S.; Qi, K.; Liu, H.; Liao, S.; Xia, B.Y. Formation of Tubular Assembly by Ultrathin $\mathrm{Ti}_{0.8} \mathrm{Co}_{0.2} \mathrm{~N}$ Nanosheets as Efficient Oxygen Reduction Electrocatalyst for Hydrogen-/Metal-air Fuel Cells. ACS Catal. 2008, 8. [CrossRef]

101. Kuang, M.; Wang, Q.; Ge, H.; Han, P.; Gu, Z.; Al-Enizi, A.M.; Zheng, G. CuCoOx/FeCOOH Core-shell Nanowires as an Efficient Bifunctional Oxygen Evolution and Reduction Catalyst. ACS Energy Lett. 2017, 1-23. [CrossRef]

102. Deng, Y.P.; Jiang, Y.; Luo, D.; Fu, J.; Liang, R.; Cheng, S.; Bai, Z.; Liu, Y.; Lei, W.; Yang, L.; et al. Hierarchical Porous Double-Shelled Electrocatalyst with Tailored Lattice Alkalinity towards Bifunctional Oxygen Reactions for Metal-air Battery. ACS Energy Lett. 2017, 1-20. [CrossRef] 